March 2016

"Assessment of Post-merger Coordinated Effects: Characterization by Simulations"

Marc Ivaldi and Vicente Lagos 


\title{
Assessment of Post-merger Coordinated Effects: \\ Characterization by Simulations
}

\author{
Marc Ivaldi \\ and \\ Vicente Lagos \\ Toulouse School of Economics
}

This version, March 21th, 2016

\begin{abstract}
This paper aims to evaluate the coordinated effects of horizontal mergers by simulating their impact on firms' critical discount factors. We consider a random coefficient model on the demand side and heterogeneous price-setting firms on the supply side. Results suggest that mergers strengthen the incentives to collude among merging parties, but weaken the incentives of non-merging parties, with the former effect being stronger. To assess the magnitudes of these effects, we introduce the concepts of Asymmetry in Payoffs and Change in Payoffs effects, which allow us to identify appropriate screening tools according to the relative pre-merger payoffs of merging parties.
\end{abstract}

Keywords: Assessment - Collusion - Coordinated effects - Critical Discount Factor - Merger Simulation 


\section{Introduction}

The coordinated effects that could be induced by a merger are defined as the increase in the incentives for merging parties (insiders) and non-merging parties (outsiders) to explicitly or tacitly collude. Two types of effects can be identified in the literature. First, with fewer firms in the market, a merger could lessen the costs of coordinating and monitoring a cartel. ${ }^{1}$ Second, as the merged firm internalizes the pricing externalities among its brands, its pricing incentives are modified, which in turn affects firms' payoffs and induces a change in their incentives to collude. ${ }^{2}$

So far, the competition authorities' assessment of coordinated effects has mainly focused on the first type of effects. Notably, the 2004 European Horizontal Merger Guidelines (EHMG) establishes four conditions for the presence of coordinated effects, that is to say: 1) the ability to reach a common understanding of the terms of coordination; 2) the ability to monitor potential deviations; 3 ) the existence of deterrent mechanisms; and 4), the presence of external sustainability. To our understanding, all these steps refer to structural characteristics of markets and/or the nature of the interactions between competitors. ${ }^{3}{ }^{4}$ While these elements are indeed crucial for an assessment of coordinated effects, none of them explicitly considers the impact of mergers on firms' pricing behavior. ${ }^{5}$

In this vein, our aim here is to characterize the risks of coordinated effects that are driven by the internalization of pricing externalities among the merging parties' brands, taking as given the four preceding conditions. To do so, we use a simulation setting with a demand specified according to a random coefficient discrete choice model and a supply side composed by heterogeneous single-product firms that

\footnotetext{
${ }^{1}$ Ivaldi, Jullien, Rey, Seabright and Tirole (2003), identify a list of relevant market characteristics that may affect the sustainability of collusion

${ }^{2}$ Davis (2006) evaluates the impact of a merger on firms' collusion and defection payoffs. A simulation approach is used, considering a setting of price competition with differentiated products and linear demands.

${ }^{3}$ See Paragraph 41 of the European Horizontal Merger Guidelines (2004), which contains the conditions necessary for coordination to be sustainable.

${ }^{4}$ See Aigner et al. (2006) for a review of the evolution of coordinated effects assessment within the EU

${ }^{5}$ For a detailed analysis of European Commission decisions involving coordinated effects assessments, refer to the following papers. (i) Aigner et al. (2006), for the Sony/BMG and Impala cases, show how the Commission used data on prices in order to search for evidence of coordination in the past. In addition, the qualitative analysis mainly focuses on product heterogeneity and market transparency. (ii) In Amelio et al. (2009), for the ABF/GBI Business case, It is explained that the Commission identified some structural changes in the market that would make (tacit) collusion easier to implement, monitor and sustain. Among the critical factors are: the decrease in the number of competitors, the enhancement of market transparency, more effective punishment of deviations, the reduction on incentives to deviate and the increase on competitors' symmetry. (iii) Finally, Motta (2000), for the Airtours/First Choise case explains that the Commission applied the concept of joint dominance and argued that the merger would increase the risk of collusion on capacities.
} 
compete in prices. Using a large set of simulated markets, we measure the impact of a merger on firms' payoffs under three different competition scenarios: one period static Nash-equilibrium, perfect-collusion, and defection from collusion.

Unlike case studies, a simulation approach has the major advantage of allowing for the characterization of risks of coordinated effects under heterogeneous demand and supply conditions. Furthermore, this approach provides a large set of simulated markets, which can be relied upon to identify the economic conditions driving the effects of a merger. In particular, each simulated market is built from the combination of four elements: 1 ) a set of $N$ consumers; 2) an indirect utility function with random coefficients; 3) a set of single-product firms with heterogeneous marginal costs, who compete in prices; and 4), products with differentiated quality attributes. In each simulation, the number of consumers and firms is kept constant. However, for each market, consumer preferences, firm marginal costs and product characteristics are randomly drawn from a set of chosen distributions.

The simplest setting of repeated interaction under the traditional grim-trigger strategies is used to model collusion. ${ }^{6}$ A given firm is willing to collude only when the present value of its collusion payoffs is higher than the present value of its most profitable defection strategy. The Critical Discount Factor (hereinafter $\mathrm{CRDF}$ ) is then defined as the minimum discount factor that makes collusion profitable. The change in coordination incentives induced by a merger is measured by the variation in the value of the CRDF.

A merger has two different effects on merging parties' incentives to collude. First, the asymmetry among merging parties in terms of their relative payoffs affects the post-merger CRDF. Specifically, the CRDF of the merged firm is relatively closer to the pre-merger CRDF of the larger merging party. The reason is that the payoffs of the larger merging party have more weight on the post-merger decision to collude. It is what we define as the Asymmetry in Payoffs (AP) effect. Second, since the merging parties internalize the negative externality among their brands that stems from the undercutting of prices, they charge higher equilibrium prices and become less aggressive when deviating from collusion prices.7 This effect - which we define as Change in Payoffs (CP) effect - increases the merged firm equilibrium payoffs, but decreases its deviation payoffs. In other words, on the one hand, the $\mathrm{CP}$ effect makes collusion less profitable, while, on the other hand, it increases firms' incentives to collude. Thus, the direction and

\footnotetext{
${ }^{6}$ A given firm sets the collusive price, if and only if, all the other firms set the collusive price in the previous periods. Any defection from collusion triggers retaliation by rival firms, which consists of playing the one-period static Nash equilibrium during all the subsequent periods. See Friedman (1971).

7 This result is also supported by Brito et al. (2013). Performing a merger simulation analysis with data from the U.S. wet shaving industry, the authors find that merging parties' defection prices are indeed increased after the merger.
} 
magnitude of the $\mathrm{CP}$ effect depends on which of these forces dominates. Regarding the impact of the merger on outsider firms, the merger only increases their equilibrium payoffs. This makes the defection strategy more profitable for outsider firms, and therefore, decreases their incentives to collude.

The simulation results suggest that the impact of the merger on the merging parties' incentives to deviate is significantly stronger than its impact on equilibrium payoffs. Thus, a merger can be used as a commitment device to increase the incentives to coordinate among insiders. The results also suggest that, while the impact on the merged firm's CRDF can be substantial after the merger, the impact on outsiders' CRDFs is moderate. Moreover, through a set of sensitivity analyses, we draw some interesting conclusions regarding the impact of efficiency gains and higher product differentiation on firms' CRDFs. For instance, the results suggest that the presence of efficiency gains tends to reinforce the impact of the merger on firms' CRDFs (i.e., by increasing the incentives for insiders to collude and by lowering the incentives for outsiders to collude) .8

In addition, we offer a novel approach for assessing the change in the merged firm's CRDF. On the one hand, in the case of a merger between two symmetric firms (in terms of payoffs), the magnitude of the change is mainly driven by the $\mathrm{CP}$ effect. Thus, for these types of mergers, the assessment should rely on screening tools able to capture the size of the pricing externality. On the other hand, in certain mergers involving two asymmetric firms (in terms of payoffs), the magnitude of the change is mainly driven by the AP effect. ${ }^{9}$ Consequently, in this scenario, the magnitude of the change is directly related to the degree of pre-merger asymmetry between the merging parties, in terms of their incentives to collude.

This paper is related to a strand of economic literature that studies how mergers affect firms' incentives to collude via the use of simulation techniques. For instance, Davis and Huse (2010) present the first empirical merger simulation model in a differentiated product market to study coordinated effects. They focus on the merger between Hewlett Packard and Compaq in the network server market. Their results show that the CRDF of insiders would decrease after a merger, while the CRDF of outsiders would increase. Similarly, Brito et al. (2013) simulate the coordinated effects of mergers and partial horizontal acquisitions in the wet shaving industry. The study finds that both partial and full acquisitions generate a decrease in the CRDF of acquiring firms while increasing the CRDFs of the remaining firms in the market.

\footnotetext{
${ }^{8}$ Nevertheless, there is a non-negligible percentage of simulated cases where the efficiency gains actually offset the impact of the merger on non-merging parties. Thus, an interesting research venue would be to explore the direction of the effect for these specific cases.

${ }^{9}$ We define two types of mergers between asymmetric firms, namely, (i) when the larger firm has the higher incentives to collude and (ii), when the larger firm has the lower incentives to collude. This distinction is important as it is shown that only mergers from the former type have the potential to generate a significant impact on firms' CRDFs.
} 
Consistent with our results, both Davis and Huse (2010) and Brito et al. (2013) find that the effect on insiders is considerably stronger than on outsiders. ${ }^{10}$

Note that our results are indeed consistent with the findings of previous empirical papers. However, we contribute to the literature in three additional ways. First, our simulation approach allows us to test the robustness of the results for a broad range of consumer and firm characteristics. Second, to the best of our knowledge, this is the first paper that incorporates the impact of efficiency gains and product differentiation with the coordinated effects of mergers. Third, we provide useful guidelines for the assessment of coordinated effects. In particular, it is shown that the magnitude of change in CRDF can be measured by existing screening tools.

Finally, it is important to highlight that the results derived here are to be interpreted only qualitatively. An empirical verification of the main conclusions is certainly an interesting venue for future empirical research.

The rest of the paper is organized as follows. Section 2 introduces the model of demand and supply, and the simple collusion scheme proposed to characterize the coordinated effects of a merger. Section 3 summarizes the basic characteristics of the simulation setting. Section 4 contains the main simulation results and develops a set of sensitivity analyses. Section 5 describes how the assessment of coordinated effects can be related to the AP and CP effects. Lastly, Section 6 presents our main conclusions.

\section{The model}

\subsection{Discrete choice model with random coefficients}

Closely following the methodology proposed by Berry (1994) and Berry, Levinsohn, and Pakes (1995), we assume that consumer choices are expressed by means of a model of demand with random coefficients. The main advantage of this model is that it encompasses much more realistic patterns of own-price and crossprice elasticities between different products and firms. ${ }^{11}$

\footnotetext{
${ }^{10}$ Table C.1 in Appendix C summarizes the main results from these papers.

${ }^{11}$ As explained by Nevo (2000), in contrast to a simple Logit demand model where substitution between products is driven completely by market shares, a random coefficient model of demand yields cross-price elasticities that are larger for products that are closer substitutes in terms of their characteristics. Moreover, this methodology has been widely used in the field of empirical industrial organization and competition economics in order to measure the competitive effects of mergers.
} 
Specifically, we consider a set of $N$ consumers, who buy at most one unit of a product $j$. Preferences are represented by a random utility model, where product $j$ provides the following level of (indirect) utility to consumer $n$ :

$$
U_{j, n}=\beta_{1, n} x_{1, j}+\beta_{2, n} x_{2, j}-\alpha_{n} p_{j}+\varepsilon_{j, n}
$$

where $x_{1, j}$ and $x_{2, j}$ represent product characteristics that determine the quality of product $j, p_{j}$ is the price of product $\mathrm{j}$ and $\varepsilon_{j, n}$ is an idiosyncratic term related to both: products and individuals. ${ }^{12}$ We assume that the characteristic $x_{1, j}$ is drawn from a continuous random variable with distribution $F_{x_{1}}$, while the second characteristic $x_{2, j}$ is assumed to be discrete, taking values 0 or 1 , according to the discrete distribution $F_{x_{2}}$. Moreover, note that all the parameters are specific to each individual: $\beta_{1 . n}=\beta_{1}+\tilde{\beta}_{1, n}, \beta_{2 . n}=\beta_{2}+\tilde{\beta}_{2, n}$, and $\alpha_{n}=\alpha+\tilde{\alpha}_{n}$, where $\tilde{\beta}_{1, n}, \tilde{\beta}_{2, n}$ and $\tilde{\alpha}_{n}$ are random variables that follow known distributions $F_{\widetilde{\beta}_{1}}, F_{\widetilde{\beta}_{2}}$ and $F_{\widetilde{\alpha}}$, respectively. Having both continuous and discrete quality attributes renders the model more general, and allows us to capture a broader range of preferences. ${ }^{13}$

In addition, consumers face an outside option, which provides them the level of utility:

$$
U_{0, n}=x_{0}+\tilde{x}_{0, n}+\varepsilon_{0, n}
$$

where the term denoted by $\tilde{x}_{0, n}$ is drawn from a continuous random variable, with distribution $F_{\tilde{x}_{0}}$.

Thus, for a given vector of prices $p$, and assuming independence between consumer idiosyncrasies for product characteristics and the error term, the market share of product $j$ is given by the following expression:

$$
s_{j}(p)=\int_{A_{j}} d F\left(\tilde{\beta}_{1}, \tilde{\beta}_{2}, \tilde{\alpha}, \tilde{x}_{0}, \varepsilon\right)=\int_{A_{j}} d F\left(\tilde{\beta}_{1}\right) d F\left(\tilde{\beta}_{2}\right) d F(\tilde{\alpha}) d F\left(\tilde{x}_{0}\right) d F(\varepsilon),
$$

\footnotetext{
12 Note that this indirect utility function can be derived from a quasi-linear utility function. It does not contain income explicitly, because when consumers compare between different products $\left(U_{j, n} \lesseqgtr U_{k, n}\right)$, the income variable vanishes. As explained by Nevo (2000), the quasi-linear assumption is only reasonable for some products. For instance, it would not be an adequateassumption for the car market, where wealth effects can play a role in consumers' decisions.

${ }^{13}$ In particular, Grigolon and Verboven (2014) highlight the importance of accounting for discrete sources of market segmentation not captured by continuous product characteristics. For instance, in the car market it is crucial to account for consumer heterogeneity regarding the domestic or foreign origin of products. Because it is more general, this specification allows for more reliable estimates of market definition.
} 
with $A_{j}=\left\{\left(\tilde{\beta}_{1}, \tilde{\beta}_{2}, \tilde{\alpha}, \tilde{x}_{0}, \varepsilon\right) \mid U_{j, n} \geq U_{l, n}\right\}$, for all $l \neq j$, denoting the set of consumers that choose product $j$. Finally, we assume that the error term $\varepsilon$ is distributed according to a Type I extreme-value distribution. ${ }^{14}$

\subsection{The supply side}

We consider $M$ single-product firms. The profit function takes the simple following form:

$$
\Pi_{i}=\left(p_{i}-c_{i}\right) s_{i}(p) N
$$

where $p_{i}, c_{i}$ and $s_{i}$ are the price, the constant marginal cost and the market share of product $i$, respectively. The variable $p$ is the vector of prices of all the brands in the market, and $N$ is the number of potential consumers. Firms have complete information regarding the parameters $\beta_{1}, \beta_{2}$ and $\alpha$, and the distributions of the random parameters are assumed to be common knowledge.

Firms' marginal costs are assumed to have the following form:

$$
c_{j}=\exp \left(\gamma_{1} x_{1, j}+\gamma_{2} x_{2, j}+\omega_{j}\right)
$$

where $\gamma_{1}>0$ and $\gamma_{2}>0$ ensure that products with higher quality are more costly to produce. In addition, there is a firm-specific cost component $\omega_{j}$, which introduces heterogeneity across firms.

\subsection{A simple collusion scheme}

The baseline model considers an infinitely repeated price competition game among heterogeneous single-product firms, where collusion sustainability is evaluated under the traditional grim-trigger strategies. The present value of the current and future flow of collusion profits has to be higher than the current defection profits plus the present value of the future flow of Nash equilibrium payoffs. Thus, collusion is sustainable at period $t_{0}$ only if the following condition is satisfied for every $i$ :

\footnotetext{
${ }^{14}$ Hence, integrating-out the error term gives rise to the well-known Logit probabilities (or market shares). For further details see Nevo (2000).
} 


$$
\sum_{t=t_{0}}^{\infty} \delta_{i}^{t-t_{0}} \Pi_{i, t}^{C} \geq \Pi_{i, t}^{D}+\sum_{t=t_{0}+1}^{\infty} \delta_{i}^{t-t_{0}} \Pi_{i, t}^{N}
$$

The variables $\Pi_{i, t}^{C}, \Pi_{i, t}^{D}$ and $\Pi_{i, t}^{N}$ are the collusion payoffs, the deviation payoffs and the Nash (or equilibrium payoffs) of the static one period game, respectively. The variable $\delta_{i}$ is the discount factor. Under what we call perfect-collusion, the collusion profits are obtained by finding the vector of prices that maximizes the expected joint-profits of all the firms in the market. ${ }^{15}$ The deviation profit is obtained by maximizing the expected profit of a given firm, taking prices of rivals as given and set at the collusion level. Finally, the equilibrium payoffs are obtained by computing the one-shot Nash equilibrium in prices.

It is assumed that consumer preferences, product characteristics and firm marginal costs do not change over time, which ensures that the stage-game played by firms is identical in every period. Therefore, for a given vector of prices, the expected payoffs are time independent. Then the previous equation can be simplified to:

$$
\frac{\Pi_{i}^{C}}{\left(1-\delta_{i}\right)} \geq \Pi_{i}^{D}+\frac{\delta_{i} \Pi_{i}^{N}}{\left(1-\delta_{i}\right)}
$$

Rearranging terms we obtain the minimum value of the discount factor $\delta_{i}^{*}$ that satisfies this condition.

Definition: The Critical Discount Factor (CRDF) of firm $i$ is the lowest discount factor for which firm $i$ has an incentive to collude. It is given by:

$$
\delta_{i}^{*}=\frac{\Pi_{i}^{D}-\Pi_{i}^{C}}{\Pi_{i}^{D}-\Pi_{i}^{N}}
$$

Under this setting, every firm in the market faces a different CRDF, which is determined by the specific characteristics of each firm and its interactions with consumers and competitors (i.e., demand elasticities, marginal costs and product characteristics). A lower CRDF implies a larger set of discount factors for which collusion is profitable. Therefore, a decrease (resp., an increase) in the CRDF is interpreted as an increase (resp., a decrease) in incentives to collude.

It is important to stress that many collusive equilibria exist. Indeed, for a given combination of discount factors, there are multiple combinations of supra-competitive prices that can be sustained under

\footnotetext{
${ }^{15}$ The joint-profit maximization vector of prices is obtained by solving: $\Pi^{J P M}=\max _{p_{1}, \ldots, p_{M}} \sum_{i=1}^{M} \Pi_{i}\left(p_{1}, \ldots, p_{M}\right)$, where, as before, the term $M$ corresponds to the total number of firms in the market, and "JPM" stands for joint-profit maximization.
} 
grim-trigger strategies. In this paper, we focus on the collusive vector of prices that maximizes the jointprofits of firms mainly for two reasons. First, this approach has so far been adopted by the empirical industrial organization literature; and second, since it focuses on a particular equilibrium, it renders tractable a rather complex problem. Consequently, it seems natural to select a model that would allow us to verify the empirical results from the literature.

An alternative approach to studying coordinated effects is followed by Sabbatini (2015) who considers an equilibrium where firms share collusion gains fairly. In this situation, all firms have the same CRDF, and the assessment of coordinated effects is made by studying the impact of a merger on the set of collusion profits that can be achieved through a regime of fair distribution of gains. ${ }^{16}$ In other words, the assessment focuses on the tension between maximization of joint-profits and their fair distribution. One of Sabbatini's motivations to focus on the distributive issues of cartels rather than on joint-profit maximization is that the perfect-collusion scheme may become unfeasible under the presence of important asymmetries among firms.

\subsection{The impact of a merger on firms' prices and payoffs}

Intuitively, when two firms merge, they internalize the externalities that their pricing decisions have on one another's profits. This fact has two implications for the merged firm's payoffs: (i) the merger generates an increase in prices and payoffs under the one-shot Nash equilibrium, and (ii) the internalization of the pricing externality makes the merged firm less aggressive when (potentially) undercutting collusion prices, which in turn induces a negative change in deviation payoffs compared to collusion payoffs. ${ }^{17}$

We express these ideas through a set of propositions. First, Proposition 1 shows that the postmerger equilibrium prices of merging parties are higher after the merger. Moreover, the corollaries of Proposition 1 suggest that the payoffs of merging parties and non-merging parties are also increased (or at least unchanged). Next, Proposition 2 states that deviation prices are always lower than or equal to collusion prices. Finally, Proposition 3 derives the conditions under which the post-merger deviation prices are higher, and its corollary suggests that merging parties' deviation payoffs are lowered.

\footnotetext{
${ }^{16}$ The assessment relies on the concept of Balance Temptation Equilibrium introduced by Friedman (1971).

${ }^{17}$ Note that perfect-collusion prices and payoffs are independent of the ownership of the firms in the market. For this reason, in the rest of the paper, we omit the superscripts "post" and "pre" when referring to collusion prices and payoffs. (For further details concerning the computation of prices and payoffs, see Appendix A)
} 
Proposition 1: Consider a merger between Firms $i$ and $j$. The post-merger equilibrium prices $p_{i}^{N, p o s t}$ and $p_{j}^{N, p o s t}$ are higher than or equal to the pre-merger equilibrium prices $p_{i}^{N, p r e}$ and $p_{j}^{N, p r e}$, respectively.

See proof in Appendix A.

Corollary 1: The post-merger equilibrium payoffs of the merged firm are higher than or equal to the aggregate premerger equilibrium payoffs of Firms $i$ and $j$.

Corollary 2: The post-merger equilibrium payoffs of non-merging parties are higher than or equal to their pre-merger equilibrium payoffs.

Proposition 1 illustrates the idea that the internalization of pricing externalities results in higher post-merger equilibrium prices for the merging parties. In particular, an increase in the price of one merging party generates divested sales that are partially captured by the other merging party. This latter effect incentivizes merging parties to raise prices.

Corollary 1 relies on the fact that the merged firm has the option to set the pre-merger equilibrium prices of Firms $i$ and $j$. It is only profitable to modify these prices when they result in higher post-merger equilibrium payoffs. Corollary 2 is based on the fact that if the merged firm raises its equilibrium prices, a fraction of divested sales is captured by non-merging parties, which increases their post-merger payoffs. In addition, as prices are strategic complements, outsiders may also find it profitable to modify their own prices, thereby further increasing their post-merger equilibrium payoffs.

Proposition 2: For every Firm $k$, its pre-merger and post-merger deviation prices $p_{k}^{D, p r e}$ and $p_{k}^{D, p o s t}$ are lower than or equal to its perfect-collusion price $p_{k}^{C}$.

See proof in Appendix A.

Proposition 3: Consider a merger between Firms $i$ and $j$. If the post-merger deviation price of Firm $j$ belongs to the interval $\left[p_{j}^{D, p r e}, p_{j}^{C}\right]$, and the pricing externality that Firm $j$ exerts on Firm $i$ is stronger than the marginal effect of $p_{i}$ on $\Pi_{i}\left(p_{i}^{D, p r e}, p_{j}^{D, p o s t}, p_{-i, j}^{C}\right)$, then the post-merger deviation price of Firm $i$ is higher than its pre-merger deviation price.

See proof in Appendix A.

Corollary: If $p_{i}^{\text {post }}>p_{i}^{\text {pre }}$, then the post-merger deviation payoff of Firm i, i.e., $\Pi_{i}\left(p_{i}^{D, p o s t}, p_{j}^{D, p o s t}, p_{-i, j}^{C}\right)$, is lower than its pre-merger deviation payoff, i.e., $\Pi_{i}\left(p_{i}^{D, p r e}, p_{-i}^{C}\right)$. 
Proposition 3 formalizes the idea that, after a merger, the merging parties are less aggressive when potentially undercutting collusion prices. Specifically, the pricing externality that merging parties exert on one another prevents them from setting deviation prices that are too low. Moreover, the corollary stems from the fact that the price $p_{i}$ that maximizes $\Pi_{i}\left(p_{i}, p_{j}^{D, p o s t}, p_{-i, j}^{C}\right)$ is lower than $p_{i}^{D, p r e}$. (For further details, see the proof of Proposition 3 in Appendix A.) This implies that the aggregate post-merger deviation payoffs of Firms $i$ and $j$ are lower compared to their aggregate collusion payoffs. (i.e., $\left.\frac{\Pi_{i}\left(p_{i}^{D, p o s t}, p_{j}^{D, p o s t}, p_{-i, j}^{C}\right)+\Pi_{j}\left(p_{i}^{D, p o s t}, p_{j}^{D, p o s t}, p_{-i, j}^{C}\right)}{\Pi_{i}^{C}+\Pi_{j}^{C}} \leq \frac{\Pi_{i}\left(p_{i}^{D, p r e}, p_{-i}^{C}\right)+\Pi_{j}\left(p_{j}^{D, p r e}, p_{-j}^{C}\right)}{\Pi_{i}^{C}+\Pi_{j}^{C}}\right)$.

\subsection{Asymmetry in Payoffs and Change in Payoffs effects}

We focus on the difference between the CRDF of the merged firm and the CRDF of the merging party with lower incentives to collude, which we define as the Overall Effect of the merger.

Definition: Let $\delta_{i, j}^{* \text {,post }}$ be the CRDF of the merged firm, i.e.,

$$
\delta_{i, j}^{*, \text { post }}=\frac{\left(\Pi_{i}^{D, p o s t}+\Pi_{j}^{D, p o s t}\right)-\left(\Pi_{i}^{C}+\Pi_{j}^{C}\right)}{\left(\Pi_{i}^{D, p o s t}+\Pi_{j}^{D, p o s t}\right)-\left(\Pi_{i}^{N, \text { post }}+\Pi_{j}^{N, p o s t}\right)^{\prime}}
$$

and let $\delta_{i}^{*, p r e}$ and $\delta_{j}^{*, p r e}$ be the pre-merger CRDFs of the merging parties, which are given by:

$$
\delta_{i}^{*, p r e}=\frac{\Pi_{i}^{D, p r e}-\Pi_{i}^{C}}{\Pi_{i}^{D, p r e}-\Pi_{i}^{N, p r e}} \quad \text { and } \quad \delta_{j}^{*, p r e}=\frac{\Pi_{j}^{D, p r e}-\Pi_{j}^{C}}{\Pi_{j}^{D, p r e}-\Pi_{j}^{N, p r e}}
$$

Then, the Overall Effect of a merger between Firms $i$ and $j$ is defined as follows:

$$
O E_{i, j}=\delta_{i, j}^{*, p o s t}-\max \left\{\delta_{i}^{*, p r e}, \delta_{j}^{*, p r e}\right\} .
$$

The superscripts "post" and "pre" stand for the post-merger and pre-merger periods, respectively. Equation (9) shows how the CRDF of the merged firm is influenced by the payoffs of both merging parties. The purpose of the Overall Effect is to measure how the incentives to collude of the merger firm compare with the incentives to collude of the merging party with lower pre-merger incentives to collude. Thus, a 
negative value of the Overall Effect can be interpreted as an increase of the merged firm's incentives to collude with respect to the merging party with a higher CRDF (i.e., the highest CRDF in Equation 10).

We study now the role played by two different effects: the asymmetry in firms' pre-merger payoffs and the internalization of the pricing externality. Separating these effects should help reach a better understanding of the magnitudes of coordinated effects. Let us name them.

The Asymmetry in Payoffs (AP) effect describes situations in which the brand with relatively larger payoffs weights more heavily on the resulting CRDF of the merged firm, thus having a higher influence on its incentives to collude. For instance, if a large multinational firm acquires a small local competitor, then we would expect the resulting merged firm's CRDF to be relatively closer to the one of the larger firm.

The sign and magnitude of the Change in Payoffs (CP) effect is the result of two opposite forces triggered by a merger. As explained in Section 2.4, on the one hand, higher equilibrium payoffs increase the merged firm's CRDF while, on the other hand, lower deviation payoffs decrease the merged firm CRDF.

In order to measure the magnitude of the $\mathrm{AP}$ and $\mathrm{CP}$ effects, we define the following variable:

$$
\delta_{i, j}^{A P}=\frac{\left(\Pi_{i}^{D, p r e}+\Pi_{j}^{D, p r e}\right)-\left(\Pi_{i}^{C}+\Pi_{j}^{C}\right)}{\left(\Pi_{i}^{D, p r e}+\Pi_{j}^{D, p r e}\right)-\left(\Pi_{i}^{N, p r e}+\Pi_{j}^{N, p r e}\right)} .
$$

Note that $\delta_{i, j}^{A P}$ is just the CRDF of the merging firm, but without incorporating any change in payoffs due to the merger. Adding and subtracting $\delta_{i, j}^{A P}$ from Equation (11) yields the following decomposition of the Overall Effect into the $\mathrm{CP}$ and $\mathrm{AP}$ effects:

$$
O E_{i, j}=(\underbrace{\left(\delta_{i, j}^{*, \text { post }}-\delta_{i, j}^{A P}\right)}_{\text {CP effect }}+(\underbrace{\left.\delta_{i, j}^{A P}-\max \left\{\delta_{i}^{* \text { pre }}, \delta_{j}^{*, p r e}\right\}\right)}_{A P \text { effect }} .
$$

This formula shows that, in the extreme case where a merger does not modify the merging parties' payoffs, the Overall Effect is exactly equivalent to the AP effect. By contrast, in the case of a merger between two perfectly symmetric firms (i.e., identical CRDFs), the Overall Effect is completely driven by the CP effect. ${ }^{18}$

\footnotetext{
18 By replacing each of the CRDFs in Equation (13) by their definitions in Equations (9), (10) and (12), it is straightforward to show that, in this case, the second term on the right hand side of Equation (13) vanishes.
} 


\subsection{Non-merging parties}

As suggested by the Corollary 2 of Proposition 1, the only change induced by the merger for non-merging parties is the increase in their equilibrium payoffs. It should be always the case that $\Pi_{i}^{N, \text { post }} \geq \Pi_{i}^{N, p r e}$ for every $i$ belonging to the group of non-merging parties.

Thus, for non-merging parties, the variation in their CRDFs is always higher than (or equal to) zero, that is, $\delta_{i}^{* \text {,post }}=\frac{\Pi_{i}^{\mathrm{D}}-\Pi_{i}^{\mathrm{C}}}{\Pi_{\mathrm{i}}^{\mathrm{D}}-\Pi_{i}^{\mathrm{N}, \text { post }}} \geq \frac{\Pi_{i}^{\mathrm{D}}-\Pi_{i}^{\mathrm{C}}}{\Pi_{i}^{\mathrm{D}}-\Pi_{i}^{\mathrm{N}, \text { pre }}}=\delta_{i}^{* \text {,pre }}$. Note that in this case, we also omit the superscripts "post" and "pre" from deviation payoffs.

\section{Simulations}

The simulation setting. We simulate 3,000 markets with 10,000 consumers each, using 12 different calibrations of the demand model. In all, we have 36,000 simulated markets. ${ }^{19}$ The different calibrations vary in terms of three different dimensions: the underlying distributions of continuous characteristics of products, the underlying distribution of consumers' mean valuations for these continuous characteristics, and the underlying distribution of consumers' mean sensitivities to prices. ${ }^{20}$

The underlying structural parameters and the distributions of random coefficients are chosen in a way that the resulting distributions of pre-merger own-price and cross-price elasticities are "realistic," in the sense that their values are similar to real elasticity estimates from previous studies. Knittel and Metaxoglou (2014) made a selection of empirical articles using BLP-type models for the estimation of random coefficient Logit demands..$^{21}$ We identify relevant reference values or intervals for own-price and cross-price elasticities. ${ }^{22}$ As Table B.1 in Appendix B exhibits, own-price elasticities are in general lower than 5. However, there is an important degree of variation across industries or even across brands within the

\footnotetext{
${ }^{19} \mathrm{~A}$ high number of consumers is necessary in order to get smooth market share functions. For instance, in the extreme case of having only one representative consumer, he/she would choose his/her preferred product, and the resulting market shares would be $100 \%$ for this product, and $0 \%$ for all the other products in the market. In addition, the representative consumer's preferred choice could be constant for a wide range of prices, making the market shares unresponsive to price changes. It could also be possible to find a combination of prices for which the representative consumer modifies his/her preferred choice, thus drastically changing the market share of his/her previous choice from $100 \%$ to $0 \%$ (and the market share of his/her new choice from $0 \%$ to $100 \%$ ). Therefore, the existence of a high number of consumers ensures the absence of these types of discontinuities.

${ }^{20}$ The details can be found in Appendix B.

${ }^{21}$ These articles have been published in leading general interest journals and the top industrial organization journals.

${ }^{22}$ Considering only the subset of papers that provide explicit values for own-price and/or cross-price elasticities.
} 
same industry. ${ }^{23}$ There are also empirical papers reporting higher values for own-price elasticities. ${ }^{24}$ The same high degree of dispersion can be found on cross-price elasticities estimates, but their values are consistently lower than 0.4 .

The supply side. We construct the supply side, assuming competition between five single-product firms, with heterogeneous but constant marginal costs for each firm and market. This number of firms seemed appropriate, considering that, in general, the cases raising coordinated effects concerns involve a low number of competitors, as documented by Petit (2010). ${ }^{25}$

In the case of firms offering heterogeneous products and competing in prices, the vector of prices that maximizes the joint-profits of firms (perfect-collusion) could potentially generate a situation where a firm faces a lower payoff as opposed to the non-collusive outcome. For instance, in a perfect-collusion scheme, it might be optimal to allocate a high market share to the firm with the lowest marginal cost, at the expense of high-cost firms. Consequently, since we are not allowing for side payments across competitorstherefore "winners" cannot compensate "losers" - the perfect-collusion scheme may become unfeasible, as it may not satisfy the basic participation constraint of every firm in the market. ${ }^{26}$

The game. Without loss of generality, we simulated the impact of a merger between firms 1 and 2, on the values of the CRDFs for every firm in the market. The timing of the game can be summarized as follows:

1) Nature draws the underlying consumer preference parameters and firms' cost components.

2) Nature draws the product characteristics.

3) Conditional on prices, firms can compute expected market shares.

4) The one-shot Nash equilibrium on prices is solved.

5) Consumers observe prices and product characteristics and eventually make their choice.

6) In the case of collusion, steps 4) and 5) are repeated, but solving for the vector of prices that maximizes the joint-profits of firms.

7) In the case of deviation by firm $i$, steps 4) and 5) are repeated, the price that maximizes the expected profit of firm $i$ is computed by taking other competitors' prices (set at the collusion level) as given.

\footnotetext{
${ }^{23}$ For instance, Armantier and Richard (2008) identify a mean own-price elasticity of 2.22 among airline groups in the U.S. market. The difference among groups can be significant, ranging from 1.540 to 2.785 .

${ }^{24}$ For instance, Bonnet and Dubois (2010) report an average own-price elasticity of 9.97 within the bottled water market in France (simple average across retailers and brands listed on the Table 6 of their article).

${ }^{25}$ The author lists all the European Commission cases involving remedies for coordinated effects concerns and shows that in all of them the number of firms is lower than five.

${ }^{26}$ This is indeed the main criticism made by Sabbatini (2015) to the joint-profit maximization approach. See the last paragraph of Section 2.3 above.
} 
The simulated sample. As stated before, the main advantage of a simulation approach is that it allows us to study the impact of a merger in different markets, with heterogeneous consumer preferences, firms' marginal costs and product characteristics. Most of the simulated price elasticities in this paper coincide with those found in the literature. For example, a high fraction of own-price elasticities are lower (in absolute value) than -5 and a high fraction of cross-price elasticities are lower than 0.4 . However, higher and more extreme values of both variables are also covered by the simulated sample. ${ }^{27}$

Note that for different reasons, slightly less than 16,000 observations are not considered. First, $11.96 \%$ of the sample is dropped because while computing equilibrium prices, the fixed-point algorithm used to solve the system of first-order conditions does not converge to a solution. ${ }^{28}$ Second, $13.48 \%$ of the sample is excluded because at least one of the pre-merger market shares is equal to zero. ${ }^{29}$ Third, an additional $9.66 \%$ of the sample is excluded because at least one of the own-price and/or cross-price elasticities has unrealistic extreme value..$^{30}$ Fourth, $7.86 \%$ of the sample is not considered because the perfect-collusion scheme is unfeasible prior to the merger. ${ }^{31}$ Finally, $0.62 \%$ of the sample is dropped because of other reasons. ${ }^{32}$

\section{Coordinated effects' characterization}

By definition, collusion is sustainable only if, for every firm $i$, the condition $\delta_{i} \geq \delta_{i}^{*}$ is satisfied. For this reason we study the impact of a merger on the values of post-merger CRDFs, for every firm in the market.

\footnotetext{
${ }^{27}$ Figure B.1 in Appendix B displays the simulated empirical distributions of own-price and cross-price elasticities for the different calibrations of the demand model.

${ }^{28}$ As documented by Knittel and Metaxoglou (2014), BLP-type models are highly non-linear, which can raise the issue of non-convergence. Thus, the rate of convergence can be sensitive to the selection of specific parameters of the simulation design. For instance, in our setting, by increasing the maximum number of iterations to 2000 (instead of 200), the fixed-pint algorithm reaches convergence on an extra $1.15 \%$ of the cases. However, this comes at the expense of considerably longer computation time.

${ }^{29}$ A priori this is not a problem; however, given that our purpose is to compare results across different markets, the number of competitors should be fixed. In addition, it does not make sense to estimate the impact of a merger when one (or both) of the merging parties has a market share equal to zero (recall that regardless of the market, we simulate a merger between firms 1 and 2).

${ }^{30}$ The aim is to keep realistic values for own-price and cross-price elasticities. The own-price elasticity threshold is defined as follows: $\bar{\eta}=\max \left\{\bar{\eta}_{i i}\right\}$. Where $\bar{\eta}_{i i}$ stands for the 99 th percentile value of the own-price elasticity of firm $i$ (in absolute value). While the threshold for cross-price elasticities is defined as:: $\bar{\zeta}=\max \left\{\bar{\zeta}_{i j}\right\}$. Where $\bar{\zeta}_{i j}$ stands for the $99^{\text {th }}$ percentile value of the cross-price elasticity between firms $i$ and $j$ (with $i \neq j$ ).

${ }^{31}$ At least one of the brands' perfect-collusion profits was lower than its pre-merger Nash profits. However, in all these cases, the joint-collusion profit is higher than the joint-equilibrium profits.

32 The details of the dropped observations can be found in Table B.4 in Appendix B.
} 
We consider a decrease (an increase, resp.) in the value of a given firm post-merger CRDF, as an increase (a decrease, resp.) in its incentives to collude. In this section, we focus on the impact of the merger on firms' payoffs and on the Overall Effect as defined in Section 2.5.

\subsection{The impact of the merger on firms' payoffs}

Table 1 displays the resulting price and payoff changes induced by the merger on merging (insiders) and non-merging parties (outsiders). For every scenario (Nash and deviation), the table exhibits the percentage of cases from the sample with a strictly positive or negative change in payoffs. In addition, it displays a comparison between the absolute variations in deviation payoffs with respect to Nash payoffs. The purpose is to verify whether the results are consistent with the propositions in Section 2.4, and to obtain an idea of which effect is predominant on the post-merger CRDF of the merged firm.

As stated in Propositions 1 and 3, the merged firm should have an incentive to raise prices after the merger. Indeed, the simulation results confirm this prediction as both equilibrium and deviation prices are raised after the merger. (See rows 1 and 3 in Table 1.) It means that the merged firm gets higher profits under the Nash scenario but lower per-product deviation profits. (See rows 2 and 4 in Table 1.) ${ }^{33}$ This latter result is also consistent with the corollaries of Propositions 1 and 3.

However, the most interesting result is that the negative variation in deviation payoffs is in absolute terms higher than the positive variation in Nash payoffs. (See row 5 in Table 1.) Intuitively, the reason is that, while firms' profits increase dramatically when they deviate from the collusion prices, the post-merger change in Nash payoffs is moderate. Therefore, a similar change in prices would have an asymmetric impact on payoffs.

Finally, as expected from Corollary 2 of Proposition 1, the merger has a positive impact on outsiders' equilibrium payoffs. (See row 2 in Table 1.)

\footnotetext{
${ }^{33}$ These results are in line with what has been found by Brito et al. (2013). Indeed, the results of their counterfactuals merger simulations applied to the wet-shaving industry in the U.S. suggest that both post-merger Nash and deviation prices are higher after the merger.
} 
Table 1 - Impact of the merger on firms' prices and payoffs

\begin{tabular}{ccccc}
\hline Scenario & & Variable & Insiders & Outsiders \\
\hline Nash & $(1)$ & \% of cases $\Delta \mathrm{P}^{\mathrm{N}}>0$ & $99.99 \%$ & $90.79 \%$ \\
& $(2)$ & $\%$ of cases $\Delta \Pi^{\mathrm{N}}>0$ & $100 \%$ & $99.93 \%$ \\
& & Interpretation & Anti-collusive & Anti-collusive \\
\hline Deviation & $(3)$ & \% of cases $\Delta \mathrm{P}^{\mathrm{D}}>0$ & $99.99 \%$ & No effect \\
& $(4)$ & \% of cases $\Delta \Pi^{\mathrm{D}}<0$ & $100 \%$ & No effect \\
& & Interpretation & Pro-collusive & No effect \\
\hline Comparison & $(5)$ & \% of cases $\left|\Delta \Pi^{\mathrm{D}}\right|>\Delta \Pi^{\mathrm{N}}$ & $99.98 \%$ & N/A \\
& & Prediction & Pro-collusive & Anti-collusive \\
\hline
\end{tabular}

\subsection{Post-merger discount factor variation}

Figure 1 displays histograms of the CRDF variations of the merged firm (Overall Effect) and of outsiders. The first interesting result is that, in $99.81 \%$ of the cases, the Overall Effect for the merged firm is negative. ${ }^{34}$ In other words, the coordination incentives of the merged firm are strengthened. In addition, as expected, the CRDF of non-merging parties increases in $99.79 \%$ of the cases. ${ }^{35}$ Nevertheless, the magnitude of this change is substantially lower than the impact of the merger on the merged firm. Indeed, the absolute change in the merged firm CRDF is higher than the change in outsiders' CRDFs in $97.41 \%$ of the sample. ${ }^{36}$

\footnotetext{
${ }^{34}$ There are 38 cases with a positive change in the CRDF. However, in 11 of these cases the variation is positive because post-merger collusion became unfeasible for the merged firm. This also explains the outlier value of 0.54 . From the remaining cases, in $75 \%$ of them the positive change is lower than 0.012 and in $95 \%$ of them the change is lower than 0.056 .

35 There are 43 cases with a negative change in the CRDF. However, in all these cases the change is lower than 0.0002 in absolute value.

${ }^{36}$ Without considering the $0.19 \%$ of cases where the merged firm CRDF has a positive change and the $0.21 \%$ of cases where at least one of the outsiders CRDF had a negative change.
} 
Figure 1 - Impact of the merger on firms' CRDFs

Panel a) Merged firm

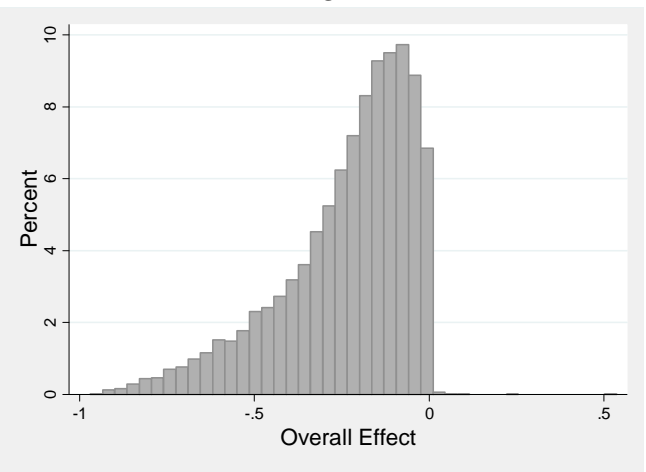

Panel b) Outsiders $\left(^{*}\right)$

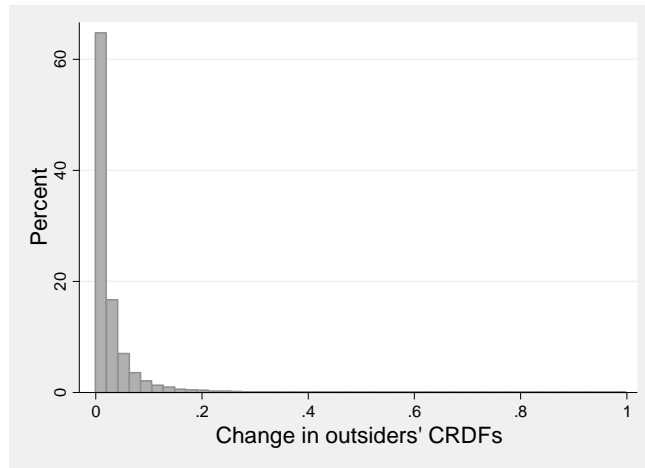

$\left.{ }^{*}\right)$ For the sake of exposition, the graph only displays changes lower than 1

\subsection{Sensitivity analysis}

In this section, we conduct a set of sensitivity analyses based on the key exogenous parameters of our simulation setting. In particular, we evaluate how the results from section 4.2 are modified according to: (i) the introduction of efficiency gains (i.e., an exogenous shock on $c_{j}$ ), (ii) a higher degree of product differentiation (i.e., an exogenous shock on $x_{1, j}$ ) and, (iii) a higher consumers' mean sensitivity to price (i.e. an exogenous shock on $\alpha$ ).

\subsubsection{Introducing efficiency gains}

A merger that generates efficiency gains - which in turn reduce marginal costs of production-allows the merging parties to price their products more aggressively. This effect increases the payoffs that the merged firm receives under every possible scenario (i.e., Nash, collusion and deviation). ${ }^{37}$ Again, the impact on the merged firm CRDF is ambiguous. On the one hand, higher collusion payoffs make coordination more attractive, which in turn induces a negative variation on its CRDF. On the other hand, higher deviation and Nash payoffs make collusion more difficult to sustain, inducing a positive change in the post-merger CRDF. Regarding the non-merging parties, efficiency gains generate exactly the opposite effects on payoffs than

\footnotetext{
${ }^{37}$ Note that with different marginal costs, the vector of prices that maximizes the joint-profits also changes. We adopt the assumption that, after the realization of efficiency gains, the vector of collusive prices adjusts accordingly. This modifies the payoffs of merging parties and non-merging parties under both the collusion and deviation scenarios.
} 
those of merging parties. ${ }^{38}$ Therefore, the direction of the resulting impact of efficiency gains, on both insiders and outsiders, depends on which of these effects dominates.

The simulations are repeated using the same set of calibrations, this time assuming that the merger generates efficiency gains that reduce the marginal costs of the merging parties. Two levels of efficiency gains are computed: (i) the exact amount necessary to mitigate the unilateral effects of the merger (low efficiency gains in Figure 2); ${ }^{39}$ (ii) twice this amount (high efficiency gains in Figure 2). ${ }^{40}$ Figure 2 displays histograms with the additional variation on firms' post-merger CRDFs induced by efficiency gains.

In general, the results suggest that, under the presence of efficiency gains, both the negative variation in the merged firm CRDF and the positive variation in outsiders' CRDFs tend to be reinforced with respect to the results shown in Section 4.2. Indeed, in the case of the merged firm, the efficiency gains induce an additional negative variation in the CRDF in $97.72 \%$ of the sample (for both levels of efficiency gains). ${ }^{41}$ Regarding the case of outsiders, the additional variation is positive on $90.7 \%$ and $91.56 \%$ of the cases with low and high efficiency gains, respectively.

Note, however, that the percentage of cases in which the efficiency gains induce a negative variation in outsiders' CRDFs is not negligible, although the magnitudes are small.42 This result is due to the fact that the decrease in deviation payoffs sometimes dominates the decrease in collusion payoffs. For further details, see Table C.2 in Appendix C.

\footnotetext{
${ }^{38}$ Outsiders have lower payoffs under every possible scenario. Lower collusion profits make coordination less attractive for outsiders, while lower deviation and lower Nash payoffs make coordination more attractive for them. The resulting impact depends on which of these effects dominates.

${ }^{39}$ The level of efficiency gains that ensures that the vector of Nash equilibrium prices is the same before and after the merger.

${ }^{40}$ We apply a similar list of criteria to the ones used in Section 3 to drop observations from the samples with efficiency gains. Thus, when merging the three databases (the original one and the ones with efficiency gains), 1,177 additional observations are lost. The main reason is that, when simulating efficiency gains, there is a higher number of markets in which the algorithm solving for equilibrium prices does not converge (after 200 iterations).

${ }^{41}$ This result is due to the fact that, for almost every market, the increase in collusion payoffs (pro-collusive effect) dominates over the increase in Nash payoffs (anti-collusive effect). For further details, see row Table C.2 in Appendix C. ${ }^{42}$ In particular, in $95 \%$ of the cases with a negative change in CRDF, the magnitude is in absolute value lower than 0.015 .
} 
Figure 2 - Impact of efficiency gains on firms' CRDFs (*)
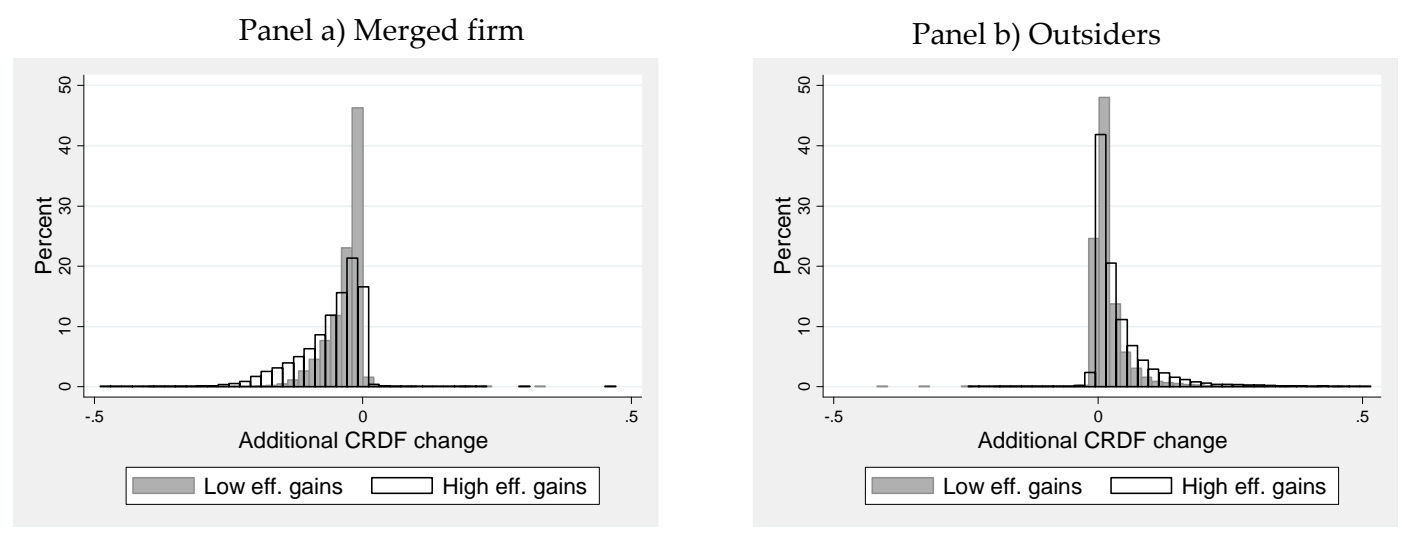

$\left.{ }^{*}\right)$ For the sake of exposition, the graphs only display changes within the interval $[-0.5,0.5]$.

\subsubsection{Product differentiation}

As it has been hinted in the literature, the impact of the degree of product differentiation is ambiguous ${ }^{43}$ In particular, higher product differentiation reduces the profits that firms obtain from undercutting collusion prices (pro-collusive effect). Yet, this differentiation also limits the intensity of competition under the punishment phase (anti-collusive effect). In addition, the degree of product differentiation also has an impact on the vector of perfect-collusion prices, which in turn modifies firms' optimal deviation strategies. Thus, all these factors simultaneously influence the direction of the final impact.

In this section, we focus on the degree of product differentiation in the product sold by the merging party $j$. Specifically, we look at the difference between $x_{1, j}$ (i.e., the continuous characteristic of the product sold by the merging party $j$ ), and the average continuous characteristic of the rest of products in the market (i.e., $\left.\frac{1}{4} \sum_{i \neq j} x_{1, i}\right) .{ }^{44}$ Then, in order to measure the impact of product differentiation on post-merger CRDFs, we simulate an exogenous $10 \%$ increase in $x_{1, j} .{ }^{45}$

Figure 3 contains two box-graphs that display the resulting relationship between the pre-merger degree of product differentiation of the merging party $j$, and the additional change in post-merger CRDF induced by the exogenous increase in $x_{1, j}$. First, in the scenario where $x_{1, j}$ is higher than the average

\footnotetext{
${ }^{43}$ For further details see Ivaldi et al. (2003).

${ }^{44}$ For the purpose of the sensitivity analysis, we choose Firm 1 as the merging party $j$.

${ }^{45}$ When merging both databases (the original one and the one with higher values of $x_{1, j}$ ), 726 observations are lost. The reason is that, after applying the criteria to clean both datasets (specified in Table B.4 in Appendix B), the observations dropped in each of them do not perfectly match.
} 
continuous characteristic of other brands in the market (i.e., a value higher than 0 in the $x$-axis), higher product differentiation is mostly associated with a decrease in the merged firm CRDF (in $96.35 \%$ of the sample), and with an increase of outsiders' CRDFs (in $85.2 \%$ of the sample). Second, in the scenario where $x_{1, j}$ is lower than the average continuous characteristic of other brands in the market (i.e., a value lower than 0 in the $x$-axis), the effect of lower product differentiation is ambiguous and the magnitudes are considerably lower than in the previous scenario. ${ }^{46}$

Thus, at least for the case of a merging party with a high continuous attribute, the impact of higher product differentiation is similar to the impact of efficiency gains. (See Tables C.2 and C.3 in Appendix C.)

\section{Figure 3 - Impact of product differentiation on firms' CRDFs $\left(^{*}\right)$}

Panel a) Merged firm $(* *)(* * *)$

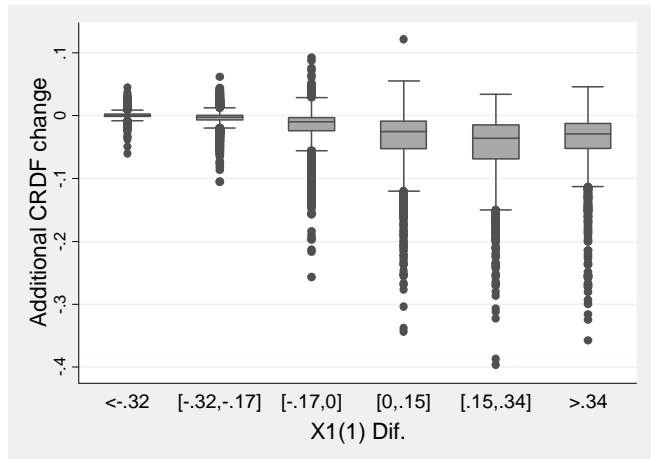

Panel b) Outsiders $(* *)(* * *)$

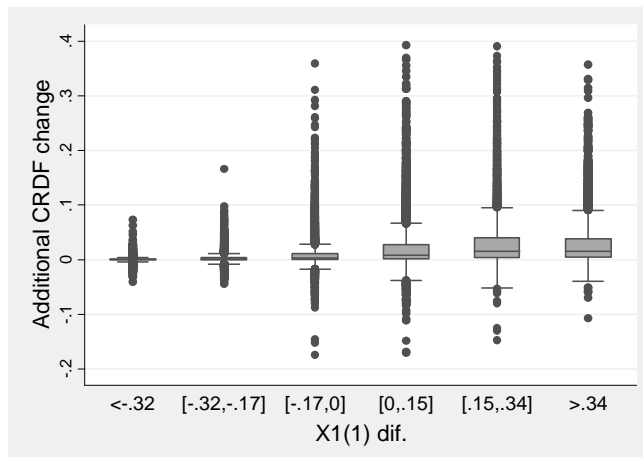

${ }^{*}$ ) For the sake of exposition, the graphs only display changes within the interval [-0.4, 0.4].

$(* *)$ The term "X1(1) dif." stands for the pre-merger difference between $x_{1,1}$ and the average continuous characteristic from the rest of the products in the market.

$\left.{ }^{* * *}\right)$ The thresholds displayed in the $\mathrm{x}$-axis are delimited by the $10^{\text {th }}, 25^{\text {th }}, 50^{\text {th }}, 75^{\text {th }}$ and $90^{\text {th }}$ percentile values.

\subsubsection{Consumers' mean price sensitivity}

The impact of a higher $\alpha$ should be threefold. First, a higher $\alpha$ should make competition fiercer, thus increasing firms' incentives to engage in collusion. Second, it should make deviations more profitable, because consumers become more responsive to price cuts. Third, since consumers are more sensitive to

\footnotetext{
46 In this scenario we refer to lower product differentiation because the exogenous increase of the continuous characteristic of product $j$ makes it more similar to the average product in the market.
} 
price, firms' collusion profits should be reduced. Therefore, the direction of the resulting impact should be ambiguous. ${ }^{47}$

We introduce a $10 \%$ exogenous shock on $\alpha$ in every simulated market. ${ }^{48}$ Its impact on firms' CRDFs is negative in $56.42 \%$ and $60.65 \%$ of cases, for the merged firm and outsiders, respectively. (See Figure C.1 in Appendix C. $)^{49}$ Consequently, it is not possible to draw precise conclusions regarding the impact of $\alpha$ on post-merger CRDFs. ${ }^{50}$

\section{Understanding the magnitude of coordinated effects}

In this section we provide a general guide for understanding the interaction of the Asymmetry in Payoffs (AP) and Change in Payoffs (CP) effects, which is important for assessing the magnitude of change in the merged firm CRDF. On the one hand, in the case of a merger between two symmetric firms in terms of premerger payoffs, the internalization of the pricing externality is what mainly drives the Overall Effect. On the other hand, in the case of a merger between asymmetric firms in terms of pre-merger payoffs, what matters for assessment purposes is the magnitude of the AP effect.

\subsection{The merged firm}

\subsubsection{A merger between two symmetric firms}

In this section, we consider symmetric merging parties in terms of their pre-merger equilibrium payoffs. For these types of mergers, the magnitude of the Overall Effect should be mostly explained by the CP effect. In this situation, a natural indicator to capture the size of the pricing externality between two brands that

\footnotetext{
${ }^{47}$ In parallel, we conduct a sensitivity analysis regarding consumers' mean valuation for the continuous characteristic (i.e., the parameter $\beta_{1}$ ), which can be also interpreted as a change in $\alpha$. Indeed, a lower $\beta_{1}$ should make price competition fiercer (equivalent to an increase in $\alpha$ ). The reason is that now consumers care relatively less about quality (in relation to price). Therefore, the impact of $\beta_{1}$ on firms' incentives to collude should also be ambiguous.

${ }^{48}$ When merging both databases (the original one and the one with higher values of $\alpha$ ), 1,075 observations are lost. The main reason is that, in the modified dataset, there is a higher number of markets where at least one of the market shares is equal to zero.

${ }^{49}$ In addition, note that the directions of the impact on insiders and outsiders are not correlated.

${ }^{50}$ As anticipated in Footnote 47, the exogenous increase in $\beta_{1}$ has an ambiguous impact on firms' incentives to collude. In particular, its impact on firms' CRDFs is negative for the merged firm and outsiders, in $41.46 \%$ and $31.59 \%$ of the cases in the sample, respectively.
} 
are imperfect substitutes is given by the diversion ratio, i.e., the proportion of sales that are divested from one brand to another as a result of a raise in prices. Practitioners typically use this tool for several purposes, including the assessment of unilateral effects, the measurement of the degree of substitutability between two brands, and the definition of relevant markets. ${ }^{51}{ }^{52}$ In addition, some recent literature suggests that diversion ratios can be used to establish indices that quantify firms' incentives to coordinate prices. ${ }^{53}$

In the simulated sample, merging parties are identified as symmetric when the pre-merger ratio between the equilibrium payoffs of the larger and smaller merging parties is close to one. Note that in the rest of the paper, every time we distinguish between larger and smaller merging parties, we refer to their relative sizes in terms of pre-merger equilibrium payoffs, unless we explicitly state something different. Panel a) of Figure 4a displays the histogram of the Overall Effect for these symmetric firms, distinguishing mergers with low and high values of the pre-merger diversion ratios. Observe that, as expected, mergers with higher diversion ratios have on average a stronger impact on the change in CRDF.

\section{Figure 4a - The magnitude of $\triangle C R D F$ (Merged firm) - Very symmetric equilibrium payoffs ${ }^{*}$ )}
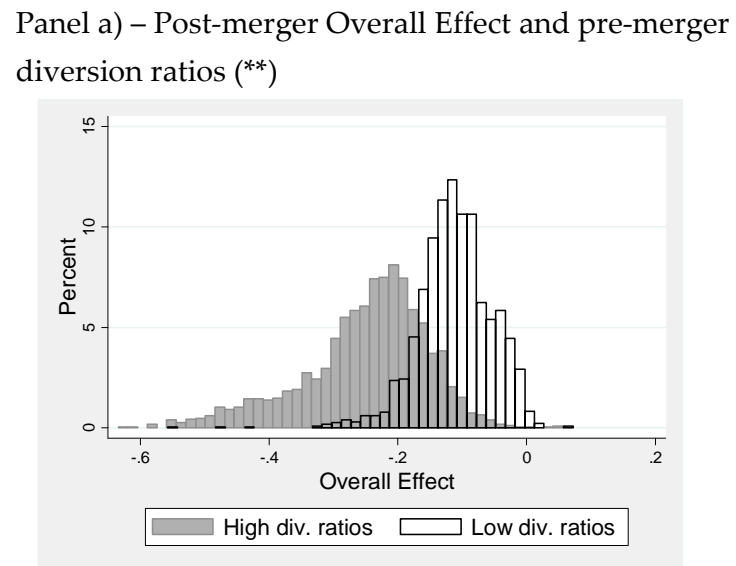

Panel b) - Post-merger AP and CP

effects

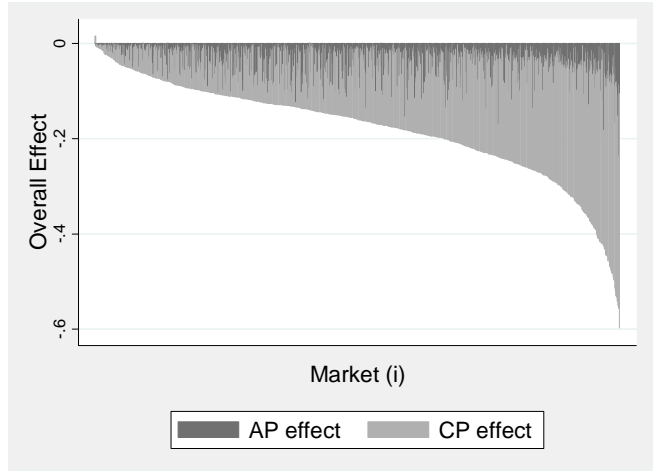

$\left(^{*}\right)$ The ratio of pre-merger equilibrium payoffs is lower than the $25^{\text {th }}$ percentile value (very symmetric firms).

$\left.{ }^{(*)}\right)$ Where "High diversion ratios" ("Low diversion ratios") stand for markets in which the pre-merger diversion ratios between merging parties' products are both higher (lower) than their $50^{\text {th }}$ percentile value.

\footnotetext{
${ }^{51}$ According to the 2004 European Horizontal Merger Guidelines, the unilateral effects (or non-coordinated effects) of a merger are defined as follows: "A merger may significantly impede effective competition in a market by removing important competitive constraints on one or more sellers, who consequently have increased market power." (See Paragraph 24.)

52 See for instance the report "Diversion ratios: why does it matter where customers go if a shop is closed?" published by Oxera. Available at: http://www.oxera.com/getmedia/12fcf7e5-4496-4e7f-bc79-a36457c92f1f/Diversion-ratios(updated) 1.pdf.aspx?ext=.pdf

53 See Moresi et al. (2011 and 2015). The CPPI and cGUPPI indexes measure the incentives of two firms to engage in a specific kind of parallel accommodating conduct.
} 
In addition, Panel b) contains a bar-graph that displays the fraction of the Overall Effect that is explained by both AP (i.e., the dark gray fraction of each bar in the graph) and CP (i.e., the light-gray fraction of each bar in the graph) effects, for each simulated market (displayed in ascending order with respect to the magnitude of the Overall Effect). As anticipated, in these types of mergers, most of the change is due to the $\mathrm{CP}$ effect. Furthermore, note that when the degree of payoff asymmetry is higher, the magnitude of the Overall Effect that is due to the $\mathrm{CP}$ effect still can be deduced by the pre-merger diversion ratios between the merged firm's products. (See Panel a) of Figure C.2 in Appendix C.)

Finally, it is interesting to evaluate how the magnitudes of the Overall Effect are related to premerger own-price elasticities. Traditionally, the competition assessment of the effects of a merger involves the definition of a relevant market, which is closely related to the study of firms' own-price elasticities. ${ }^{54}$ In particular, high own-price elasticities would reflect the presence of intense competition from rival firms and/or the possibility to define a broad relevant market. Under these conditions, a merger would raise less anticompetitive concerns.

Figure $4 \mathrm{~b}$ contains histograms that display the Overall Effect of the merger, distinguishing mergers with low and high own-price elasticities of the merging parties' products. The results clearly suggest that the magnitude of the Overall Effect is not related to the pre-merger own-price elasticities. The reason is that this variable is not a good predictor of the impact of the merger on firms' payoffs. For instance, Figure C.3 in Appendix C displays histograms of the change in firms' equilibrium and deviation payoffs, distinguishing merging parties with high and low own-price elasticities, and merging parties with high and low diversion rations between their products. Results suggest that diversion ratios display a significantly better performance when predicting the post-merger change in payoffs. ${ }^{55}$

Result 1: For mergers between symmetric firms, the construction of a screening tool that aims to predict the impact of the merger on the merged firm CRDF should be based on the pre-merger diversion ratios between the brands produced by the merged firm.

\footnotetext{
${ }^{54}$ For instance, the merger guidelines published in 2006 by the International Competition Network, institution that gathers many competition authorities from around the world; suggest market definition as the first step of a merger assessment. Document available in the lollowing link http://www.internationalcompetitionnetwork.org/uploads/library/doc321.pdf

55 These results are in line with recent articles that suggest the degree of direct product substitutability among merging firms as a better screening tool for an assessment of the competitive effects of a merger. See for instance, Farrell and Shapiro (2010), who propose the use of margins and the extent of direct substitution between the merged firm's products, in order to assess the unilateral effects of mergers.
} 
Figure $4 \mathrm{~b}$ - The magnitude of $\triangle C R D F$ (Merged firm) - Very symmetric equilibrium payoffs (*)

Panel a) - Low pre-merger diversion ratio $\left(^{* *}\right)(* * *)$

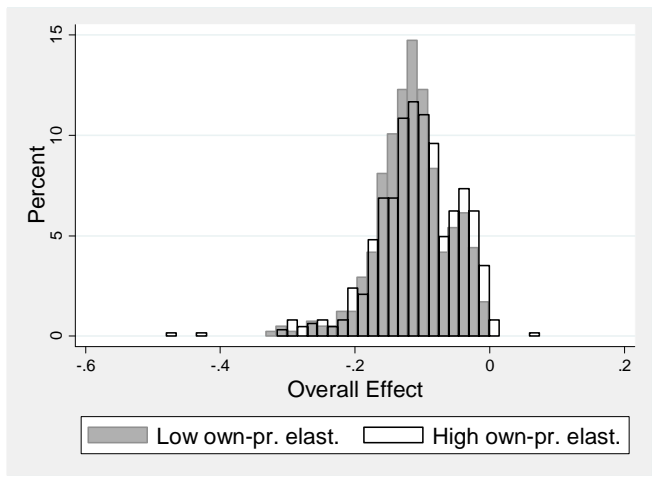

Panel b) - High pre-merger diversion ratio $\left(^{* *}\right)\left({ }^{* * *}\right)$

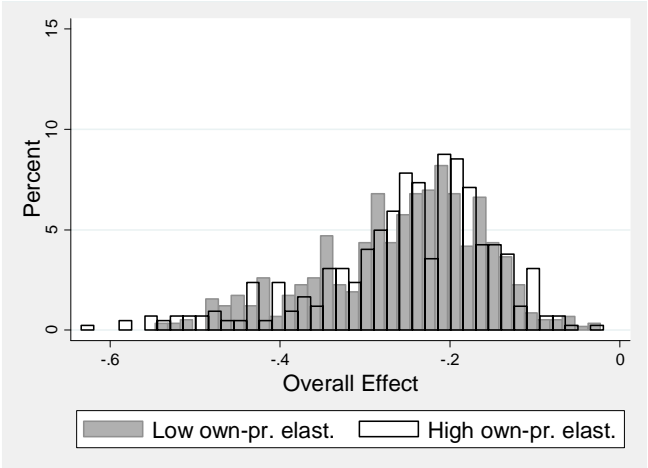

$\left(^{*}\right)$ The ratio of pre-merger equilibrium payoffs is lower than the $25^{\text {th }}$ percentile value (very symmetric firms).

$(* *)$ Where "High diversion ratios" ("Low diversion ratios") stand for markets in which the pre-merger diversion ratios between merging parties' products are both higher (lower) than their $50^{\text {th }}$ percentile value.

${ }^{(* * *)}$ Where "Low own-price elasticities" ("High own-price elasticities") stand for merging firms' with pre-merger own-price elasticities lower (higher) than the $25^{\text {th }}\left(75^{\text {th }}\right)$ percentile value (in absolute value).

\subsubsection{A merger between two asymmetric firms}

In this section, we consider asymmetric merging parties in terms of their pre-merger equilibrium payoffs. For these types of mergers, the payoffs of the smaller firm have a low influence on the post-merger payoffs of the merged firm. Thus, the resulting CRDF is close to the pre-merger one of the larger firm. For this reason, it is necessary to distinguish two cases when the larger firm has, between the two merging parties: (a) the lowest pre-merger CRDF and, (b) the highest pre-merger CRDF. This distinction is important because, as it is shown, only mergers of the first type have the potential to generate a significant Overall Effect. In the simulated sample, merging parties are identified as asymmetric when the ratio between the pre-merger equilibrium payoffs of the larger and smaller merging parties is significantly higher than one.

Case (a) The larger firm has the lower pre-merger CRDF

This is the more intuitive scenario. For instance, it corresponds to the case of a larger firm acquiring a small maverick firm (i.e., a firm with a very high CRDF). Basically, the larger firm "absorbs" the smaller one and the Overall Effect is almost equal to the pre-merger difference on CRDFs (i.e., $\max \left\{\delta_{i}^{* \text { pre }}, \delta_{j}^{*, p r e}\right\}-$ $\left.\min \left\{\delta_{i}^{*, p r e}, \delta_{j}^{*, p r e}\right\}\right)$. Panel a) in Figure 5a displays a scatter-graph between the pre-merger CRDF difference 
and the magnitude of the Overall Effect. Note that there is an almost perfect correlation between both variables. Additionally, Panel b) contains a bar-graph that displays the fraction of the Overall Effect that is explained by both AP (i.e., the dark-gray fraction of each bar in the graph) and $\mathrm{CP}$ (i.e., the light-gray fraction of each bar in the graph) effects, for each simulated market (displayed in ascending order with respect to the magnitude of the Overall Effect). As anticipated, most of the change is due to the AP effect. ${ }^{56}$

When the degree of payoff asymmetry is lower and the $\mathrm{CP}$ effect starts playing a more important role in explaining the Overall Effect, the fraction that is due to the AP effect still can be deduced by the premerger CRDFs' asymmetry. However, the magnitude of this effect becomes weaker as the firms are more symmetric. (See Panel b) of Figure C.2 in Appendix C.) $)^{57}$

Figure 5a- The magnitude of $\triangle C R D F$ (Merged firm) - Very asymmetric equilibrium payoffs (*)

\section{Case (a) The larger firm has the lower pre-merger CRDF}

Panel a) - Post-merger Overall Effect and pre-merger CRDF difference

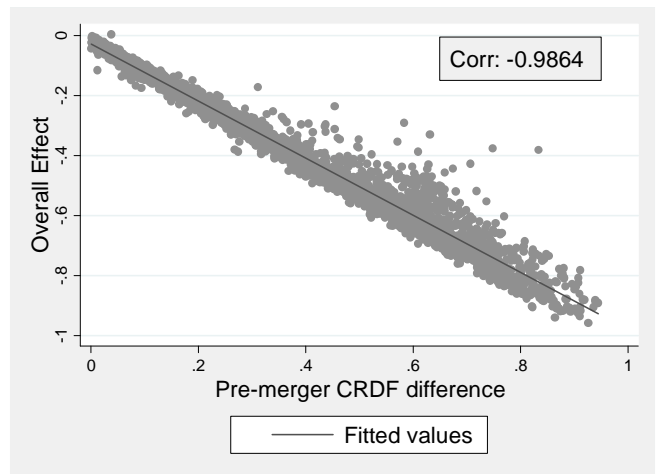

Panel b) - Post-merger AP and CP effects

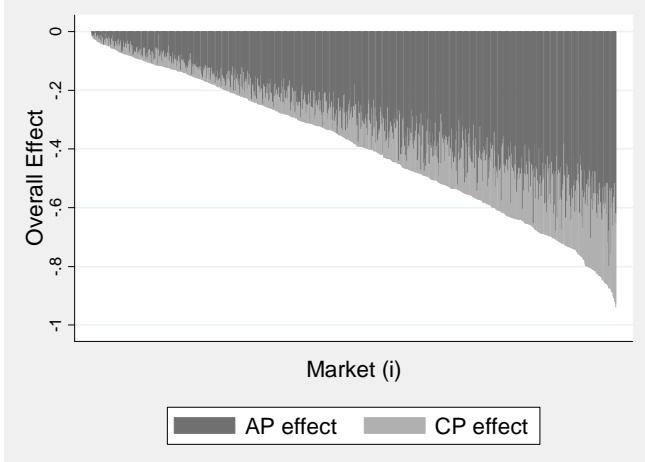

$\left.{ }^{*}\right)$ The ratio of pre-merger equilibrium payoffs is higher than the $75^{\text {th }}$ percentile value (very asymmetric firms).

Certainly, the most natural candidates to predict the degree of pre-merger asymmetry between firms in terms of their incentives to collude are market shares and cross-price elasticities. ${ }^{58}$ Specifically,

\footnotetext{
${ }^{56}$ In addition, as shown in the previous section, the fraction of the Overall Effect that is due to the CP effect can be approximated by the magnitudes of the diversion ratios. See Panel a) of Figure C.2 in Appendix C.

${ }^{57}$ Panel b) of Figure C.2 contains scatter-graphs that display the resulting relationship between the pre-merger CRDF difference and the magnitude of the AP effect, for different degrees of asymmetry between the merging parties in terms of their pre-merger equilibrium payoffs. The results show that the magnitude of the AP effect is always correlated with the pre-merger CRDF difference, independently of the degree of payoff asymmetry. However, the magnitudes of the AP effect are significantly stronger for mergers between asymmetric firms.

${ }^{58}$ Ivaldi et al. (2003) suggest that, among other factors, firms' market shares and the degree of product differentiation can influence their incentives to engage in collusion.
} 
larger firms and firms with lower cross-price elasticities (i.e., with higher degree of product differentiation) should be less tempted to deviate from collusion. ${ }^{59}$ The reason is that they would capture only a small fraction of consumers from rival firms (pro-collusive effect). However, a higher degree of product differentiation should make competition under the Nash equilibrium less intense, weakening the incentives to collude.

In order to measure the degree of pre-merger asymmetry between merging parties in terms of cross-price elasticities, we look at the ratio of their weighted cross-price elasticities, i.e., $\frac{w c p e_{s p}}{w c p e_{l p}}$, where $s p(l p)$ stands for the merging party with the smaller (larger) pre-merger equilibrium payoffs. The variable $w p c e_{i}$ is defined as follows:

$$
w c p e_{i}=\sum_{j \neq i} \frac{s_{j}}{\sum_{j \neq i} s_{j}} \cdot \frac{\partial s_{i}}{\partial p_{j}} \cdot \frac{p_{j}}{s_{i}}
$$

where $s_{i}$ and $p_{i}$ are the pre-merger market share and price of Firm $i$, respectively.

First, Panel a) of Figure 5b displays histograms of the Overall Effect, distinguishing mergers with high and low ratios of pre-merger weighted cross-price elasticities (CPEs in Figure 5b). Results suggest that, merging parties that are more asymmetric in terms of this variable generate on average a stronger impact. Second, Panel b) of Figure 5b displays histograms of the Overall Effect, distinguishing mergers with high and low ratios of pre-merger market shares. ${ }^{60}$ Results show that, this variable is not a good predictor of the Overall Impact.

Result 2: For mergers between asymmetric firms where the larger firm has the lower pre-merger $C R D F$, the construction of a screening tool that aims to predict the impact of the merger on the merged firm CRDF should be based on the degree of pre-merger asymmetry between the merging parties in terms of their cross-price elasticities.

\footnotetext{
${ }^{59}$ Note that market shares and price elasticities are endogenous. Indeed, the presence of asymmetries in terms of these variables is probably the result of asymmetries in terms of other market characteristics, such as marginal costs, product attributes, firms' pricing decisions, and consumer preferences, among others. However, since these variables are more easily observed by policy makers, it is convenient to derive qualitative conclusions as a function of them.

${ }^{60}$ It is defined as the ratio between the market shares of the larger and smaller firms.
} 
Figure $5 b$ - The magnitude of $\triangle C R D F$ (Merged firm) - Very asymmetric equilibrium payoffs (*)

\section{Case (a) The larger firm has the lower pre-merger CRDF}

Panel a) - Ratio of pre-merger cross-price elasticities $(* *)$

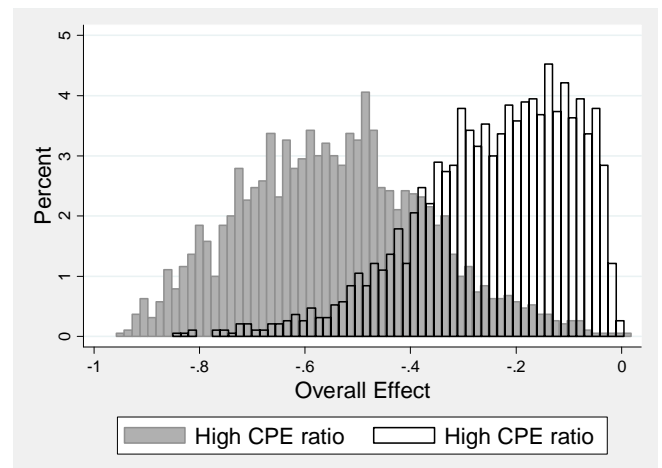

Panel b) - Ratio of pre-merger market shares

$(* * *)$

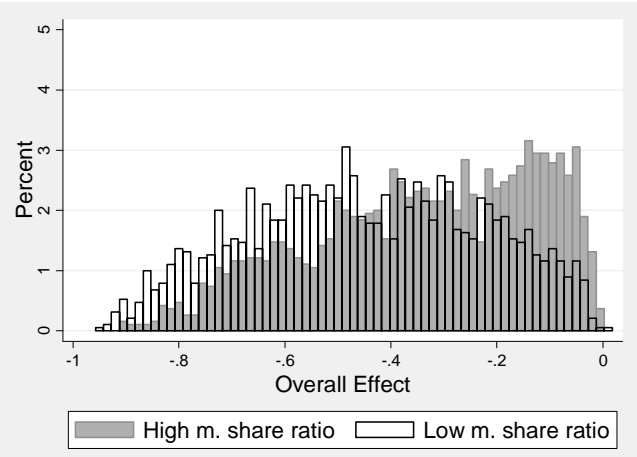

$\left(^{*}\right)$ The ratio of pre-merger equilibrium payoffs is higher than the $75^{\text {th }}$ percentile value (very symmetric firms).

${ }^{(* *)}$ Where "High cross-price elasticity (CPE) ratio" ("Low cross-price elasticity ratio") stands for firms with a pre-merger crossprice elasticity ratio higher (lower) than the $50^{\text {th }}$ percentile value.

${ }^{(* * *)}$ Where "High market share ratio" ("Low market share ratio") stands for firms with a pre-merger market share ratio higher (lower) than the $50^{\text {th }}$ percentile value (in absolute value).

Case (b) The larger firm has the higher pre-merger CRDF

This is the less intuitive case. For instance, it corresponds to a scenario in which a large established firm with low incentives to collude acquires a smaller competitor with high incentives to collude. For these types of mergers, the CRDF of the merged firm is mostly influenced by the payoffs of the merging party with low incentives to collude (i.e., the larger firm), which in turn implies a weak magnitude for the AP effect. In addition, provided that the degree of asymmetry between the merging parties is high, the smaller firm only exerts a weak externality on the pricing behavior of the larger firm, and thus, the CP effect should also be weak.

To verify this prediction, Panel a) of Figure 6 displays the histogram of the Overall Effect for asymmetric firms, distinguishing mergers that qualify as Case (a) or Case (b). The results clearly confirm that the Overall Effect is substantially lower for Case (b). ${ }^{61}$

\footnotetext{
${ }^{61}$ As the firms become more symmetric, the Overall Effect is driven by the size of the pricing externality, and the distinction between Cases (a) and (b) becomes less relevant. Figure C.4 in Appendix C displays histograms of the Overall Effect, distinguishing mergers in Cases (a) and (b), for different degrees of asymmetry between the merging parties in terms of their pre-merger equilibrium payoffs. The results show that, only for mergers between asymmetric firms, the magnitude of the Overall Effect is significantly different between Cases (a) and (b).
} 
Result 3: For mergers between asymmetric firms where the larger firm has the higher pre-merger CRDF, the risk of coordinated effects is certainly low

\section{Figure 6 - The magnitude of $\triangle C R D F$ (Merged firm) - Very asymmetric equilibrium payoffs $\left({ }^{*}\right)$ \\ Cases (a) and (b)}

Panel a) - Post-merger Overall Effect, comparison between Cases a) and b)

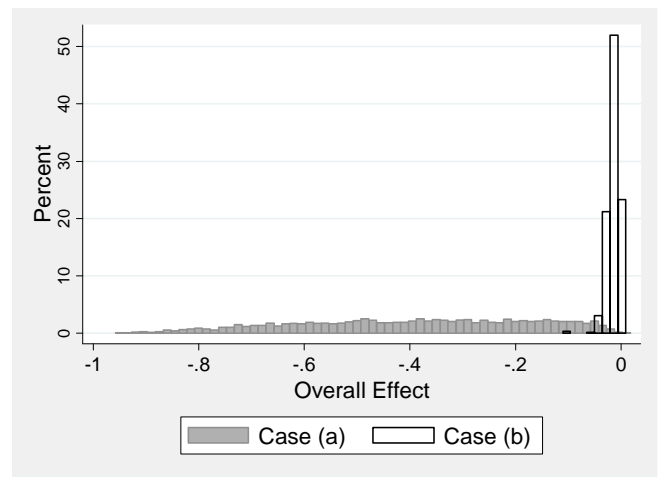

Panel b) - Pre-merger CRDF ratio and pre-merger cross-price elasticity ratio $\left.{ }^{* * *}\right)$

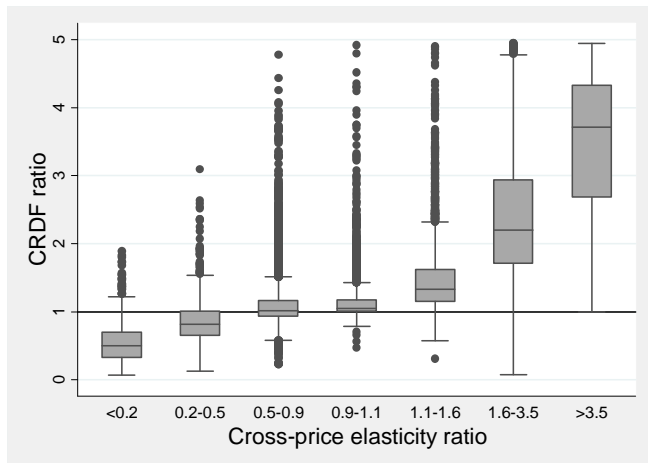

$\left({ }^{*}\right)$ The ratio of pre-merger equilibrium payoffs is higher than the $7^{\text {th }}$ percentile value.

$\left.{ }^{* *}\right)$ For the sake of exposition, the graphs only display CRDFs ratios lower than 4.97 ( $90^{\text {th }}$ per. value).

$\left.{ }^{* * *}\right)$ The thresholds displayed in the $\mathrm{x}$-axis are delimited by the $10^{\text {th }}, 25^{\text {th }}, 50^{\text {th }}, 75^{\text {th }}$ and $90^{\text {th }}$ percentile values.

How to distinguish between Cases (a) and ( $b$ )

Panel b) of Figure 6 contains box-graphs that display the relationship between the pre-merger ratio of merging-parties' CRDFs (i.e., $\frac{C R D F_{s p}}{C R D F_{l p}}$ ) and the ratio of their pre-merger weighted cross-price elasticities. ${ }^{62}$ The interpretation of the graph axes is the following: (i) on the y-axis, if the CRDF ratio is higher (lower) than one, it means that the smaller (larger) firm has the higher pre-merger CRDF; (ii) on the x-axis, if the cross-price elasticity ratio is higher (lower) than one, it means that the smaller (larger) firm has the higher cross-price elasticity. Results suggest that; (i) when the cross-price elasticity ratio is significantly higher than one, then the CRDF of the smaller firm is in general higher (i.e., previously defined as Case a)), (ii) when the cross-price elasticity ratio is significantly lower than one, then the CRDF of the larger firm is in general higher (i.e., previously defined as Case b)), and (iii), when the cross-price elasticity is close to one, then the

${ }^{62}$ As before, $s p(l p)$ stands for the merging party with the smaller (larger) pre-merger equilibrium payoffs. 
identity of the firm with the higher CRDF is more ambiguous. Note that these results, as the rest of the results from this paper, are to be interpreted only qualitatively.

\subsection{Outsiders}

The magnitude of the impact on outsiders' CRDFs should be explained by the impact of the merger on their pricing decisions. Recall that the only change faced by non-merging parties is the increase in their Nashequilibrium payoffs. Thus, the stronger the $\mathrm{CP}$ effect, and the higher the fraction of divested sales that goes from the merged firm to non-merging parties, then the stronger the impact of the merger on outsiders should be.

Figure C.5 in Appendix C displays histograms of the change in a particular outsider CRDF, distinguishing mergers with low and high pre-merger diversion ratios - from products sold by the merged firm to the product sold by this particular outsider firm - and mergers with weak and strong CP impact on the merged firm CRDF. The results show that the impact is on average higher for mergers with a strong $\mathrm{CP}$ effect, whereas the pre-merger diversion ratios do not seem to be good predictors of the impact of the merger on the outsider CRDF.

Result 4: For the case of outsiders, the magnitude of the CRDF change is significantly stronger for mergers with a strong CP effect. However, the diversion ratios - from products sold by the merged firm to the product sold by a particular outsider firm - are not good predictors of the magnitude of the change.

\section{Conclusions}

The simulation results suggest that a merger can strengthen the coordination incentives of insiders. However, the merger also makes outsiders less willing to collude since deviation becomes more attractive for them. The magnitudes of the results suggest that, while the impact of a merger on the merged firm CRDF can be substantial, its impact on outsiders' CRDFs is moderate. These results are robust to a wide variety of parameters of the demand and supply model, and coincide with what has been found in previous empirical papers. 
We provide a novel approach for the assessment of coordinated effects, separating the impact of the merger on the merged firm CRDF into two different effects: namely, the $\mathrm{AP}$ and $\mathrm{CP}$ effects. In the case of a large firm acquiring a small maverick firm, the impact of the merger is mainly explained by the degree of pre-merger asymmetry between the merging parties in terms of their incentives to collude. In the case of a merger between two symmetric firms, the impact of the merger is mainly driven by the size of the pricing externality. In particular, in the former case, the assessment should be based on the pre-merger cross-price elasticities of the merging parties, while in the latter case the assessment should be built on diversion ratios. Finally, for the case of outsiders, results suggest that only mergers that generate a strong $\mathrm{CP}$ effect have the potential to generate a significant impact on their CRDFs.

Acknowledgments We are very thankful to Yossi Spiegel, Patrick Rey, Pedro Pereira, Paulo Furquim de Azevedo, Jan Bouckaert and two anonymous referees for insightful comments on an earlier version. The paper has also benefited from interesting discussions with participants at the 2014/2015 Competition Policy Workshop at Toulouse School of Economics and at the 2015 CRESSE Conference held in Greece.

Simulations code The original versions of the code and protocol used in this paper were created by Jérôme Foncel, researcher at the University of Lille in France.

\section{Appendix A}

\section{Properties of the profit function}

We consider a market with $M$ single-product firms that compete in prices. The profit function of Firm $i$ has the simple following form:

$$
\Pi_{i}=\left(p_{i}-c_{i}\right) s_{i}(p) N,
$$

where $s_{i}(p)$ is the market share of Firm $i$, such that $\frac{\partial s_{i}(p)}{\partial p_{i}} \leq 0$ and $\frac{\partial s_{k}(p)}{\partial p_{i}} \geq 0$ for all $k \neq i$. We assume that the profit function $\Pi_{i}\left(p_{i}, p_{-i}\right)$ is strictly concave in $p_{i}$, which implies that $\frac{\partial^{2} \Pi_{i}\left(p_{i}, p_{-i}\right)}{\partial p_{i}^{2}}<0$ for all $p_{i}$ and $p_{-i}$. In addition, we assume that prices $p_{i}$ and $p_{k}$ are strategic complements, i.e., $\frac{\partial^{2} \Pi_{i}\left(p_{i,} p_{-i}\right)}{\partial p_{i} \partial p_{k}} \geq 0$ for all $i$ and $k$, with $k \neq i$.

\section{Nash payoffs}

The pure strategy Nash equilibrium in prices satisfies the following system of first-order conditions:

$$
\Lambda_{i}\left(p^{N, p r e}\right)=s_{i}\left(p^{N, p r e}\right)+\left(p_{i}^{N, p r e}-c_{i}\right) \frac{\partial s_{i}\left(p^{N, p r e}\right)}{\partial p_{i}}=0, \forall i,
$$

where $p^{N, p r e}$ is the vector of pre-merger equilibrium prices. The strict concavity of the profit function guarantees that the first-order conditions are sufficient for a Nash equilibrium. (See Tirole 1988.)

Let us define $R_{i}\left(p_{-i}\right)$ as the pre-merger best response function of Firm $i$ given prices $p_{-i}$. This function satisfies $\Lambda_{i}\left(R_{i}\left(p_{-i}\right), p_{-i}\right)=0$, where $\Lambda_{i}=\frac{\partial \Pi_{i}}{\partial p_{i}}$. From the strict concavity assumption, it follows that there is a unique $p_{i}$ such that $p_{i}=R_{i}\left(p_{-i}\right)$. In addition, considering the assumption of strategic complementarity of prices, then $\frac{\partial \mathrm{R}_{i}}{\partial p_{k}} \geq 0$ for all $k \neq i$. 
After a merger between Firms $i$ and $j$, the pure strategy Nash equilibrium in prices satisfies the following system of firstorder conditions:

$$
\begin{gathered}
\bar{\Lambda}_{i}\left(p^{N, p o s t}\right)=\Lambda_{i}\left(p^{N, p o s t}\right)+\left(p_{j}^{N, p o s t}-c_{j}\right) \frac{\partial s_{j}\left(p^{N, p o s t}\right)}{\partial p_{i}}=0 \\
\bar{\Lambda}_{j}\left(p^{N, p o s t}\right)=\Lambda_{j}\left(p^{N, p o s t}\right)+\left(p_{i}^{N, p o s t}-c_{i}\right) \frac{\partial s_{i}\left(p^{N, p o s t}\right)}{\partial p_{j}}=0 \\
\bar{\Lambda}_{k}\left(p^{p o s t}\right)=0, \forall k \neq\{i, j\},
\end{gathered}
$$

where $p^{N, p o s t}$ denotes the vector of post-merger equilibrium prices. The post-merger best response functions of the merging parties $\bar{R}_{i}\left(p_{-i}\right)$ and $\bar{R}_{i}\left(p_{-i}\right)$ satisfy $\bar{\Lambda}_{i}\left(\bar{R}_{i}\left(p_{-i}\right), p_{-i}\right)=0$ and $\bar{\Lambda}_{j}\left(\bar{R}_{j}\left(p_{-j}\right), p_{-j}\right)=0$, and the post-merger best response function of Firm $k$ for all $k \neq\{i, j\}$ satisfies $\bar{\Lambda}_{k}\left(\bar{R}_{k}\left(p_{-k}\right), p_{-k}\right)=0$.

Proposition 1: Consider a merger between Firms $i$ and $j$. The post-merger equilibrium prices $p_{i}^{N, p o s t}$ and $p_{j}^{N, \text { post }}$ are higher than or equal to the pre-merger equilibrium prices $p_{i}^{N, p r e}$ and $p_{j}^{N, p r e}$, respectively.

Proof: First, considering that $\left(p_{j}-c_{j}\right) \frac{\partial s_{j}(p)}{\partial p_{i}} \geq 0$ and $\left(p_{i}-c_{i}\right) \frac{\partial s_{i}(p)}{\partial p_{j}} \geq 0$ for relevant values of $p_{i}$ and $p_{j}$, then the post-merger best response functions of Firms $i$ and $j$ satisfy $\bar{p}_{h}=\bar{R}_{h}\left(p_{-h}\right) \geq p_{h}=R_{h}\left(p_{-h}\right)$ for $h=\{i . j\}$ and all $p_{-h}$. In addition, the post-merger best response function of Firm $k$ for all $k \neq\{i, j\}$, satisfies $\bar{R}_{k}\left(p_{-k}\right)=R_{k}\left(p_{-k}\right)$ for all $p_{-k}$. Thus, $\bar{R}_{l}\left(p_{-l}\right) \geq R_{l}\left(p_{-l}\right)$ for all $l$.

Second, assuming that prices are strategic complements, i.e., $\frac{\partial^{2} \Pi_{l}}{\partial p_{l} \partial p_{r}} \geq 0$, implies that $\frac{\partial R_{l}}{\partial p_{r}} \geq 0$ for all $l$ and $r \neq l$, and ensures that $\frac{\partial \bar{R}_{k}}{\partial p_{r}} \geq 0$ for $k \neq\{i, j\}$ and all $r \neq k$. Moreover, assuming that $\frac{\partial^{2} s_{j}}{\partial p_{i} \partial p_{k}} \geq 0$ and $\frac{\partial^{2} s_{i}}{\partial p_{j} \partial p_{k}} \geq 0$ for $k \neq\{i, j\}$, ensures that $\frac{\partial \bar{R}_{h}}{\partial p_{k}} \geq 0$ for $h=\{i . j\}$ and all $k \neq\{i, j\}$.

Finally, assuming that $\frac{\partial^{2} s_{j}}{\partial p_{i} \partial p_{i}} \leq 0$ and $\frac{\partial^{2} s_{i}}{\partial p_{j} \partial p_{j}} \leq 0$ guarantees strict concavity of the merged firm profit function. Thus, by Theorem 4 of Milgrom and Roberts (1994), the post-merger Nash equilibrium in prices satisfies $p_{l}^{N, p o s t} \geq p_{l}^{N, p r e}$ for all $l$.

\section{Collusion payoffs}

The joint-profit maximization (or perfect-collusion) vector of prices $p^{c}$ is obtained by solving: $\Pi^{J P M}=\max _{p_{1}, \ldots, p_{M}} \sum_{i=1}^{M} \Pi_{i}\left(p_{1}, \ldots, p_{M}\right)$.

We only consider cases in which the perfect-collusion payoffs of every firm in the market are higher than the one-period Nash equilibrium payoffs, i.e., $\Pi_{i}\left(p_{1}^{C}, \ldots, p_{M}^{C}\right) \geq \Pi_{i}\left(p_{1}^{N, p r e}, \ldots, p_{M}^{N, p r e}\right)$ for all $i$. Finally, note that the vector of collusion prices is independent of the ownership of the different products in the market. In other words, a merger does not have any impact on $p^{c}$.

\section{Pre-merger deviation payoffs}

The pre-merger deviation payoffs of Firm $i$ are given by:

$$
\Pi_{i}^{D, p r e}=\Pi_{i}\left(p_{i}^{D, p r e}, p_{-i}^{C}\right)=\left(p_{i}^{D, p r e}-c_{i}\right) s_{i}\left(p_{i}^{D, p r e}, p_{-i}^{C}\right) N,
$$

where $p_{i}^{D, p r e}$ is the pre-merger deviation price of Firm $i$ and $p_{-i}^{C}$ is the vector of collusion prices for the rest of the firms in the market. The price $p_{i}^{D, p r e}$ satisfies:

$$
\Lambda_{i}\left(p_{i}^{D, p r e}, p_{-i}^{C}\right)=s_{i}\left(p_{i}^{D, p r e}, p_{-i}^{C}\right)+\left(p_{i}^{D, p r e}-c_{i}\right) \frac{\partial s_{i}\left(p_{i}^{D, p r e}, p_{-i}^{C}\right)}{\partial p_{i}^{D, p r e}}=0 .
$$

\section{Post-merger deviation payoffs}

The post-merger deviation payoffs of the merged firm are given by:

$$
\Pi_{i, j}^{D, \text { post }}=\Pi_{i}\left(p_{i}^{D, \text { post }}, p_{j}^{D, \text { post }}, p_{-i, j}^{C}\right)+\Pi_{j}\left(p_{i}^{D, \text { post }}, p_{j}^{D, \text { post }}, p_{-i, j}^{C}\right)=\left(p_{i}^{D, p o s t}-c_{i}\right) s_{i}\left(p_{i}^{D, \text { post }}, p_{j}^{D, p o s t}, p_{-i, j}^{C}\right) N+\left(p_{j}^{D, p o s t}-\right.
$$




$$
\left.c_{j}\right) s_{j}\left(p_{i}^{D, p o s t}, p_{j}^{D, p o s t}, p_{-i, j}^{C}\right) N,
$$

where $p_{i}^{D, p o s t}$ and $p_{j}^{D, \text { post }}$ are the post-merger deviation prices of Firms $i$ and $j$, and $p_{-i, j}^{C}$ is the vector of collusion prices of the rest of the firms in the market. The pair of prices $p_{i}^{D, p o s t}$ and $p_{j}^{D, p o s t}$ satisfy:

$$
s_{i}\left(p_{i}^{D, p o s t}, p_{j}^{D, p o s t}, p_{-i, j}^{C}\right)+\left(p_{i}^{D, p o s t}-c_{i}\right) \frac{\partial s_{i}\left(p_{i}^{D, p o s t}, p_{j}^{D, p o s t}, p_{-i, j}^{C}\right)}{\partial p_{i}}+\left(p_{j}^{D, p o s t}-c_{j}\right) \frac{\partial s_{j}\left(p_{i}^{D, p o s t}, p_{j}^{D, p o s t}, p_{-i, j}^{C}\right)}{\partial p_{i}}=0,
$$

and,

$$
s_{j}\left(p_{i}^{D, p o s t}, p_{j}^{D, p o s t}, p_{-i, j}^{C}\right)+\left(p_{j}^{D, p o s t}-c_{j}\right) \frac{\partial s_{j}\left(p_{i}^{D, p o s t}, p_{j}^{D, p o s t}, p_{-i, j}^{C}\right)}{\partial p_{j}}+\left(p_{i}^{D, p o s t}-c_{i}\right) \frac{\partial s_{i}\left(p_{i}^{D, p o s t}, p_{j}^{D, p o s t}, p_{-i, j}^{C}\right)}{\partial p_{j}}=0 .
$$

Proposition 2: For every Firm $k$, its pre-merger and post-merger deviation prices $p_{k}^{D, p r e}$ and $p_{k}^{D, p o s t}$ are lower than or equal to its perfect-collusion price $p_{k}^{C}$.

Proof: Considering that $\frac{\partial s_{h}}{\partial p_{k}}>0$ for all $h$ and $k$, with $h \neq k$, then a deviation price higher than $p_{k}^{C}$ would jointly increase the profits of Firm $k$ and every Firm $h$, for $h \neq k$, which is not consistent with the fact that the vector of collusion prices $p^{C}$ is the one that maximizes the joint-profits of all the firms in the market. Hence, the price that maximizes Firm $k^{\prime}$ s deviation payoffs is lower than $p_{k}^{C}$.

Proposition 3: Consider a merger between Firms $i$ and $j$. If the post-merger deviation price of Firm $j$ belongs to the interval $\left[p_{j}^{D, p r e}, p_{j}^{C}\right]$, and the pricing externality that Firm $j$ exerts on Firm $i$ is stronger than the marginal effect of $p_{i}$ on $\Pi_{i}\left(p_{i}^{D, p r e}, p_{j}^{D, p o s t}, p_{-i, j}^{C}\right)$, then the post-merger deviation price of Firm $i$ is higher than its pre-merger deviation price.

Proof: Considering that prices $p_{i}$ and $p_{j}$ are strategic complements, then the price $p_{i}$ that maximizes $\Pi_{i}\left(p_{i}, p_{j}^{D, p o s t}, p_{-i, j}^{C}\right)$ for $p_{j}^{D, p o s t} \in$ $\left[p_{j}^{D, p r e}, p_{j}^{C}\right]$, is lower than $p_{i}^{D, p r e}$, which in turn implies that $\Lambda_{i}\left(p_{i}^{D, p r e}, p_{j}^{D, p o s t}, p_{-i, j}^{C}\right)<0$. Thus, considering post-merger deviation prices $p_{i}^{D, p r e}$ and $p_{j}^{D, p o s t} \in\left[p_{j}^{D, p r e}, p_{j}^{C}\right]$, and considering that the pricing externality that Firm $j$ exerts on Firm $i$, i.e., $\left(p_{j}^{D, \text { post }}-c_{j}\right) \frac{\partial s_{j}\left(p_{i}^{D, p r e}, p_{j}^{D, p o s t}, p_{-i, j}^{C}\right)}{\partial p_{i}}$, is higher than the marginal effect of $p_{i}$ on $\Pi_{i}\left(p_{i}^{D, p r e}, p_{j}^{D, p o s t}, p_{-i, j}^{C}\right)$ in absolute value, i.e., $\left|\Lambda_{i}\left(p_{i}^{D, p r e}, p_{j}^{D, p o s t}, p_{-i, j}^{C}\right)\right|$, and assuming that $\frac{\partial^{2} s_{j}}{\partial p_{i} \partial p_{i}} \leq 0$ for relevant values of $p_{i}$ and $p_{j}$, then the price $p_{i}^{D, p o s t}$ that satisfies Equation (A.9) is higher than $p_{j}^{D, p r e}$. 


\section{Appendix B}

Table B.1 - List of papers extracted from Knittel and Metaxoglou (2014)

\begin{tabular}{|c|c|c|c|c|}
\hline Journal & Authors & Industry & \multicolumn{2}{|c|}{ Observations } \\
\hline \multirow[t]{2}{*}{ Rand Journal of Economics } & Armantier and Richard (2008) & Airlines & & \\
\hline & Mean & Std. Dev & Min. & Max. \\
\hline Own-price elast. & -2.22 & 0.50 & -2.79 & -1.54 \\
\hline Cross-price elast. & 0.21 & 0.09 & 0.09 & 0.35 \\
\hline \multirow[t]{2}{*}{ Rand Journal of Economics } & Bonnet and Dubois (2010) & $\begin{array}{l}\text { Bottled Water } \\
\quad \text { (Retail) }\end{array}$ & \multicolumn{2}{|c|}{ Averages computed among brands and retailers } \\
\hline & Mean & Std. Dev & Min. & Max. \\
\hline Own-price elast. & -9.97 & 1.87 & -12.96 & -4.97 \\
\hline Cross-price elast. & 0.06 & 0.03 & 0.02 & 0.11 \\
\hline \multirow[t]{2}{*}{ Rand Journal of Economics } & Copeland (2011) & Automobile & \multicolumn{2}{|c|}{$\begin{array}{l}\text { The cross-price elasticities are computed } \\
\text { between vintages of the same model }\end{array}$} \\
\hline & Mean & Std. Dev & Min. & Max. \\
\hline Own-price elast. & -2.61 & 0.49 & -3.60 & -1.50 \\
\hline Cross-price elast. & 0.02 & 0.02 & 0.00 & 0.17 \\
\hline \multirow[t]{2}{*}{ Rand Journal of Economics } & Iizuka (2007) & Prescription Drugs & \multicolumn{2}{|c|}{$\begin{array}{l}\text { Only the average own-price elasticity is } \\
\text { provided }\end{array}$} \\
\hline & Mean & Std. Dev & Min. & Max. \\
\hline Own-price elast. & -2.3 & - & - & - \\
\hline Cross-price elast. & - & - & - & - \\
\hline \multirow[t]{2}{*}{ Rand Journal of Economics } & Nevo (2000) & $\begin{array}{l}\text { Ready-to-Eat } \\
\text { Cereals }\end{array}$ & \multicolumn{2}{|c|}{$\begin{array}{l}\text { We only report the cross-price elast. between } \\
\text { Kellogg and General Mills. Brands }\end{array}$} \\
\hline & Mean & Std. Dev & Min. & Max. \\
\hline Own-price elast. & -2.18 & 0.76 & -3.70 & -1.32 \\
\hline Cross-price elast. & 0.05 & 0.04 & 0.00 & 0.13 \\
\hline \multirow[t]{2}{*}{ Rand Journal of Economics } & Villas-Boas (2009) & Coffee (Retail) & \multicolumn{2}{|c|}{$\begin{array}{l}\text { We report the mean elasticities across } \\
\text { manufacturers }\end{array}$} \\
\hline & Mean & Std. Dev & Min. & Max. \\
\hline Own-price elast. & -7.63 & 0.66 & -8.47 & -6.80 \\
\hline Cross-price elast. & 0.04 & 0.02 & 0.01 & 0.07 \\
\hline \multirow[t]{2}{*}{ Econometrica } & Goeree (2008) & $\begin{array}{l}\text { Personal } \\
\text { Computer }\end{array}$ & & \\
\hline & Mean & Std. Dev & Min. & Max. \\
\hline Own-price elast. & -6.65 & 3.25 & -12.86 & -3.26 \\
\hline Cross-price elast. & 0.03 & 0.01 & 0.01 & 0.09 \\
\hline \multirow[t]{2}{*}{ Econometrica } & Nevo (2001) & $\begin{array}{l}\text { Ready-to-Eat } \\
\text { Cereal }\end{array}$ & \multicolumn{2}{|c|}{$\begin{array}{l}\text { We only report the cross-price elast. between } \\
\text { Kellogg and General Mills. Brands }\end{array}$} \\
\hline & Mean & Std. Dev & Min. & Max. \\
\hline Own-price elast. & -3.02 & 0.64 & -4.25 & -2.28 \\
\hline Cross-price elast. & 0.09 & 0.06 & 0.01 & 0.24 \\
\hline \multirow[t]{2}{*}{ Review of Economic Studies } & Nakamura and Zerom (2010) & Coffee & \multicolumn{2}{|c|}{$\begin{array}{l}\text { The median price elasticity from the Logit with } \\
\text { random coefficients estimation }\end{array}$} \\
\hline & Mean & Std. Dev & Min. & Max. \\
\hline Own-price elast. & -3.46 & - & - & - \\
\hline Cross-price elast. & - & - & - & - \\
\hline \multirow[t]{2}{*}{ Review of Economic Studies } & Villas-Boas (2007) & Supermarkets & & \\
\hline & Mean & Std. Dev & Min. & Max. \\
\hline Own-price elast. & -5.71 & 0.64 & -6.74 & -4.67 \\
\hline Cross-price elast. & 0.03 & 0.01 & 0.01 & 0.04 \\
\hline
\end{tabular}


Table B.2 Baseline simulations setting

\begin{tabular}{|c|c|}
\hline Parameter & Baseline Setting \\
\hline$M$ & $\begin{array}{l}\text { Number of firms is fixed to } 5 \text { for all the markets. } \\
\text { Each firm produces only one product. }\end{array}$ \\
\hline$N$ & Number of consumers is set to 10,000 for all the markets. \\
\hline NS & Number of simulations for computing the expected market shares is fixed to 10,000 for all the markets. \\
\hline$\alpha\left({ }^{*}\right)$ & It is constant within each market, but it varies across markets with uniform distribution $U_{[0, \bar{\alpha}]}$. \\
\hline$\tilde{\alpha}_{n}$ & $\begin{array}{l}\text { For a given market varies among consumers with exponential distribution } E_{1 / \sigma_{\alpha}} \text {. } \\
\text { The parameter } \sigma_{\alpha} \text { is distributed uniformly } U_{[0,7]} \text { across markets. }\end{array}$ \\
\hline$\beta_{1}\left(^{*}\right)$ & It is constant within each market, but it varies across markets with uniform distribution $U_{\left[0, \bar{\beta}_{1}\right]}$. \\
\hline$\beta_{2}$ & It is constant within each market, but it varies across markets with uniform distribution $U_{[0,3]}$. \\
\hline$\tilde{\beta}_{1, n}, \tilde{\beta}_{2, n}$ & $\begin{array}{l}\text { For a given market both vary among consumers with normal distributions } N_{\left[0, \sigma_{\beta_{1}}\right]} \text { and } N_{\left[0, \sigma_{\beta_{2}}\right]} \text {. The } \\
\text { parameters } \sigma_{\beta_{1}} \text { and } \sigma_{\beta_{2}} \text { are distributed uniformly } U_{[0,5]} \text { across markets. }\end{array}$ \\
\hline$\tilde{\varepsilon}_{n, j}, \tilde{\varepsilon}_{n, 0}$ & They are both drawn from an extreme value distribution $F_{[\lambda]}$, where the scale parameter $\lambda$ is equal to 0.5. \\
\hline$x_{1, j}(*)$ & For each market $x_{1, j}=\exp \left(\tau \cdot \xi_{j}\right)$ where $\tau=0.3$ and $\xi_{j}$ are distributed normally with $N_{\left[2, \sigma_{x_{1}}\right]}$. \\
\hline$x_{2, j}$ & For each market $x_{2, j}=\mathrm{I}\left(\eta_{j}>0\right)$ where $\eta_{j}$ are distributed normally with $N_{[0,1]}$. \\
\hline$x_{0}$ & For each market $x_{0}$ is drawn from a normal distribution $N_{[0,4]}$. \\
\hline$\tilde{x}_{n, 0}$ & $\begin{array}{l}\text { For a given market varies among consumers with normal distribution } N_{\left[0, \sigma_{x}\right]} \text {. The parameter } \sigma_{x} \text { is } \\
\text { distributed uniformly } U_{[0,3]} \text { across markets. }\end{array}$ \\
\hline$\omega_{j}$ & For each market $\omega_{j}$ is drawn from a normal distribution $N_{[0,0.05]}$. \\
\hline$\gamma_{1}, \gamma_{2}$ & Both are fixed for each market, but they vary across markets with the same uniform distribution $U_{[0,1]}$. \\
\hline$\gamma$ & $\begin{array}{l}\text { It is fixed on each market and common for all firms. It is either equal to zero (when marginal costs are } \\
\text { assumed to be constant), or vary across markets with uniform distribution } U_{[0,0.0002]} \text { (when marginal } \\
\text { costs are increasing). }\end{array}$ \\
\hline
\end{tabular}

(*) Parameters that are modified in each calibration. See Table B.3 below

Table B.3 Calibrations

\begin{tabular}{|c|c|c|c|}
\hline \multirow{2}{*}{ Calibration } & \multicolumn{3}{|c|}{ Parameters } \\
\hline & $\bar{\alpha}$ & $\bar{\beta}_{1}$ & $\sigma_{\mathrm{x}_{1}}$ \\
\hline (1) & 15 & 1.1 & 5 \\
\hline$(2)$ & 8 & 1.1 & 5 \\
\hline (3) & 3 & 1.1 & 5 \\
\hline (4) & 15 & 4 & 5 \\
\hline (5) & 8 & 4 & 5 \\
\hline (6) & 3 & 4 & 5 \\
\hline (7) & 15 & 1.1 & 2 \\
\hline (8) & 8 & 1.1 & 2 \\
\hline (9) & 3 & 1.1 & 2 \\
\hline (10) & 15 & 4 & 2 \\
\hline (11) & 8 & 4 & 2 \\
\hline (12) & 3 & 4 & 2 \\
\hline
\end{tabular}


Table B.4 Data cleaning

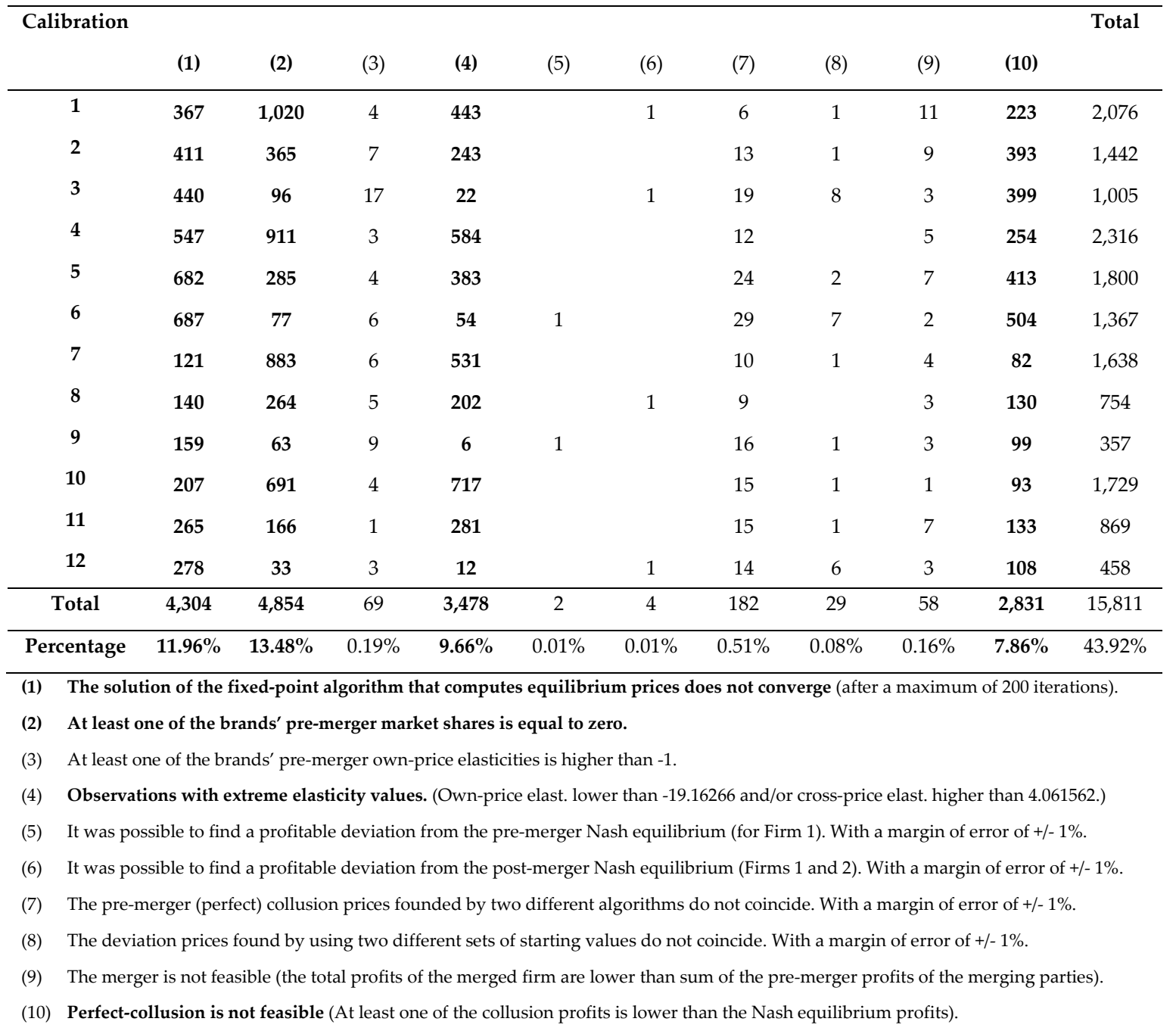

\section{Figure B.1 Empirical distributions}

Panel a) - Own-price elasticities by calibration setting

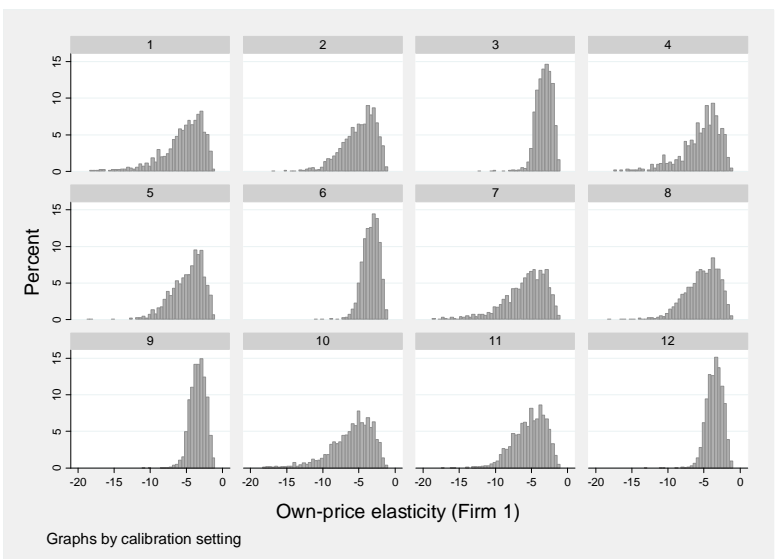

Panel b) - Cross-price elasticities by calibration setting

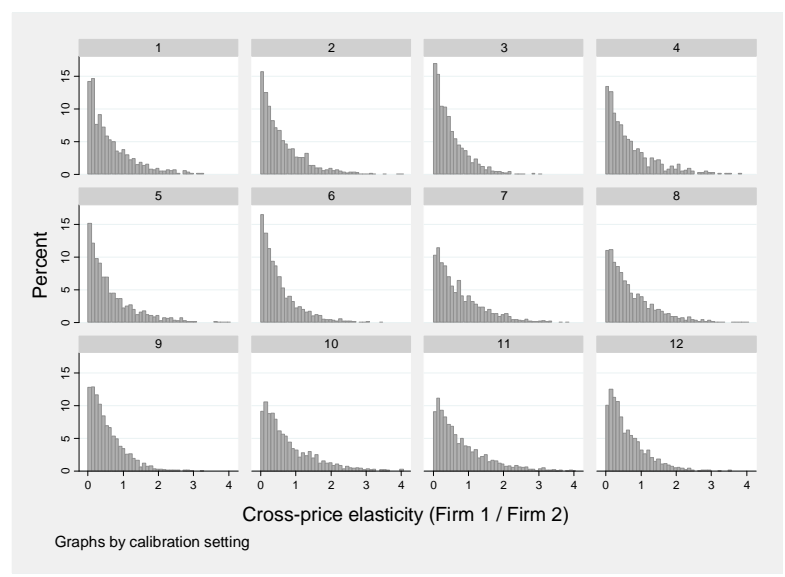




\section{Appendix C}

Table C.1 - CRDF estimates extracted from Davis and Huse (2010) and Brito et al. (2013)

\begin{tabular}{|c|c|c|c|c|c|}
\hline \multirow[b]{2}{*}{ Paper } & \multirow[b]{2}{*}{ Market } & \multirow[b]{2}{*}{ Firm $\left(^{*}\right)$} & \multicolumn{2}{|c|}{ Estimated CRDF } & \multirow[b]{2}{*}{$\%$ Var. } \\
\hline & & & Pre-merger & Post-merger & \\
\hline \multirow{9}{*}{$\begin{array}{l}\text { Davis and Huse } \\
\text { (2010) }\end{array}$} & Network server industry & Compaq & 0.303 & \multirow{2}{*}{0.246} & \multirow{2}{*}{$-61.1 \%$} \\
\hline & \multirow{2}{*}{$\begin{array}{l}\text { EU, 4-10 price segment } \\
\text { (Merger: Compaq-HP) }\end{array}$} & $\mathrm{HP}$ & 0.632 & & \\
\hline & & Unisys & 0.724 & 0.782 & $8.0 \%$ \\
\hline & Network server industry & Compaq & 0.528 & \multirow{2}{*}{0.482} & \multirow{2}{*}{$-19.3 \%$} \\
\hline & \multirow{2}{*}{$\begin{array}{c}\text { Japan, } 4-10 \text { price segment } \\
\text { (Merger: Compaq-HP) }\end{array}$} & $\mathrm{HP}$ & 0.597 & & \\
\hline & & Hitachi & 0.632 & 0.642 & $1.5 \%$ \\
\hline & Network server industry & Compaq & 0.549 & \multirow{2}{*}{0.530} & \multirow{2}{*}{$-23.9 \%$} \\
\hline & \multirow{2}{*}{$\begin{array}{l}\text { US, } 4-10 \text { price segment } \\
\text { (Merger: Compaq-HP) }\end{array}$} & $\mathrm{HP}$ & 0.697 & & \\
\hline & & Data Gen & 0.817 & 0.832 & $1.8 \%$ \\
\hline \multirow{6}{*}{ Brito et al. (2013) } & \multirow{3}{*}{$\begin{array}{l}\text { Wet Shaving Industry } \\
\text { (Merger WS-Gillette) }\end{array}$} & Wilkinson Sword & 0.815 & \multirow{2}{*}{0.260} & \multirow{2}{*}{$-68.1 \%$} \\
\hline & & Gillette & 0.262 & & \\
\hline & & A Safety Razor & 0.888 & 0.894 & $0.68 \%$ \\
\hline & \multirow{3}{*}{$\begin{array}{l}\text { Wet Shaving Industry } \\
\text { (Merger WS-WL) }\end{array}$} & Wilkinson Sword & 0.815 & \multirow{2}{*}{0.788} & \multirow{2}{*}{$-3.31 \%$} \\
\hline & & Warner-Lambert & 0.790 & & \\
\hline & & A Safety Razor & 0.888 & 0.890 & $0.23 \%$ \\
\hline
\end{tabular}

$\left.{ }^{*}\right)$ Only selected firms: merging parties and the outsider with the highest CRD

Table C.2 - The impact of efficiency gains on post-merger payoffs

\begin{tabular}{|c|c|c|c|c|}
\hline \multirow{2}{*}{ Scenario } & & \multirow{2}{*}{ Variable } & \multicolumn{2}{|c|}{ Change in payoffs } \\
\hline & & & Insiders & Outsiders \\
\hline \multirow[t]{2}{*}{ Nash } & (1) & $\%$ of cases $\Delta \Pi^{\mathrm{N}}>0$ & $99.99 \%$ & $0.01 \%$ \\
\hline & & Interpretation & Anti-collusive & $\begin{array}{l}\text { It cancels out the } \\
\text { previous effect }\left({ }^{*}\right)\end{array}$ \\
\hline \multirow[t]{2}{*}{ Deviation } & (2) & $\%$ of cases $\Delta \Pi^{\mathrm{D}}>0$ & $99.94 \%$ & $0.35 \%$ \\
\hline & & Interpretation & $\begin{array}{c}\text { It weakens the } \\
\text { previous effect }\left(^{*}\right)\end{array}$ & Pro-collusive \\
\hline \multirow[t]{2}{*}{ Collusion } & (3) & $\%$ of cases $\Delta \Pi^{\mathrm{C}}>0$ & $99.97 \%$ & $0.14 \%$ \\
\hline & & Interpretation & Pro-collusive & Anti-collusive \\
\hline \multirow[t]{4}{*}{ Comparison } & (4) & $\%$ of cases $\left|\Delta \Pi^{\mathrm{C}}\right|>\left|\Delta \Pi^{\mathrm{N}}\right|$ & $98.33 \%$ & - \\
\hline & (5) & $\%$ of cases $\left|\Delta \Pi^{\mathrm{C}}\right|>\left|\Delta \Pi^{\mathrm{D}}\right|$ & - & $83.82 \%$ \\
\hline & & Prediction & Pro-collusive & Ambiguous \\
\hline & & Observations & 38,024 & 57,036 \\
\hline
\end{tabular}

$\left(^{*}\right)$ Where "previous effect" refers to the impact of the merger before efficiency gains 
Table C.3 - The impact of higher product differentiation on post-merger payoffs

Only cases where: $X 1(1)$ dif $\left.>0{ }^{* *}\right)$

\begin{tabular}{|c|c|c|c|c|}
\hline \multirow{2}{*}{ Scenario } & & \multirow{2}{*}{ Variable } & \multicolumn{2}{|c|}{ Change in payoffs } \\
\hline & & & Insiders & Outsiders \\
\hline \multirow[t]{2}{*}{ Nash } & (1) & $\%$ of cases $\Delta \Pi^{N}>0$ & $98.69 \%$ & $5.33 \%$ \\
\hline & & Interpretation & Anti-collusive & $\begin{array}{c}\text { It weakens the } \\
\text { previous effect }\left(^{*}\right)\end{array}$ \\
\hline \multirow[t]{2}{*}{ Deviation } & (2) & $\%$ of cases $\Delta \Pi^{\mathrm{D}}>0$ & $98.65 \%$ & $2.65 \%$ \\
\hline & & Interpretation & $\begin{array}{l}\text { It weakens the } \\
\text { previous effect }\left(^{*}\right)\end{array}$ & Pro-collusive \\
\hline \multirow[t]{2}{*}{ Collusion } & (3) & $\%$ of cases $\Delta \Pi^{\mathrm{C}}>0$ & $98.69 \%$ & $3.56 \%$ \\
\hline & & Interpretation & Pro-collusive & Anti-collusive \\
\hline \multirow[t]{4}{*}{ Comparison } & (4) & $\%$ of cases $\left|\Delta \Pi^{\mathrm{C}}\right|>\left|\Delta \Pi^{\mathrm{N}}\right|$ & $98.38 \%$ & - \\
\hline & (5) & $\%$ of cases $\left|\Delta \Pi^{\mathrm{C}}\right|>\left|\Delta \Pi^{\mathrm{D}}\right|$ & - & $66.73 \%$ \\
\hline & & Prediction & Pro-collusive & Ambiguous \\
\hline & & Observations & 17,924 & 26,886 \\
\hline
\end{tabular}

$\left(^{*}\right)$ Where "previous effect" refers to the impact of the merger before efficiency gains

$\left.{ }^{(* *}\right)$ The term "X1(1) dif." stands for the pre-merger difference between the continuous characteristic of the product sold by Firm 1 and the average continuous characteristic from the rest of products in the market

Figure C.1 - Impact of higher consumers' mean price sensitivity $(\alpha)\left(^{*}\right)$

Panel a) Merged firm

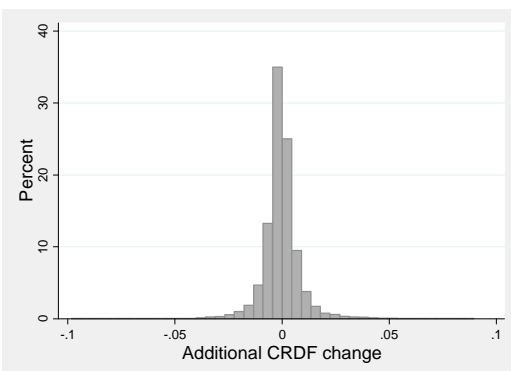

Panel b) Outsiders

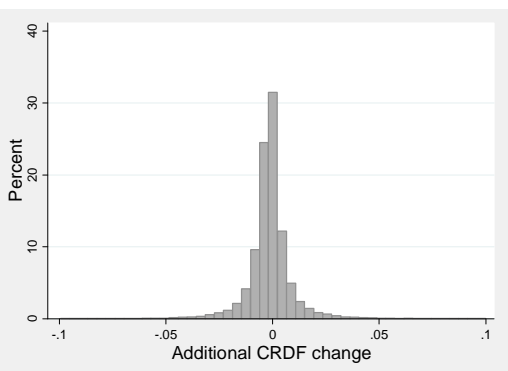

$(*)$ For the sake of exposition, the graphs only display changes within the interval [-0.1, 0.1]. 
Figure C.2 - The magnitude of the CP and AP effects (Merged firm) (*)

Panel a) CP effect $\left({ }^{*}\right)$

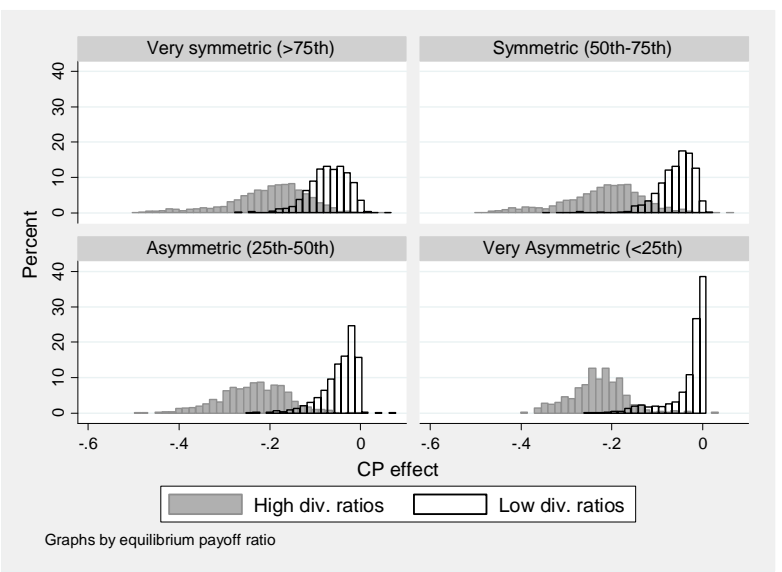

Panel b) AP effect (**)

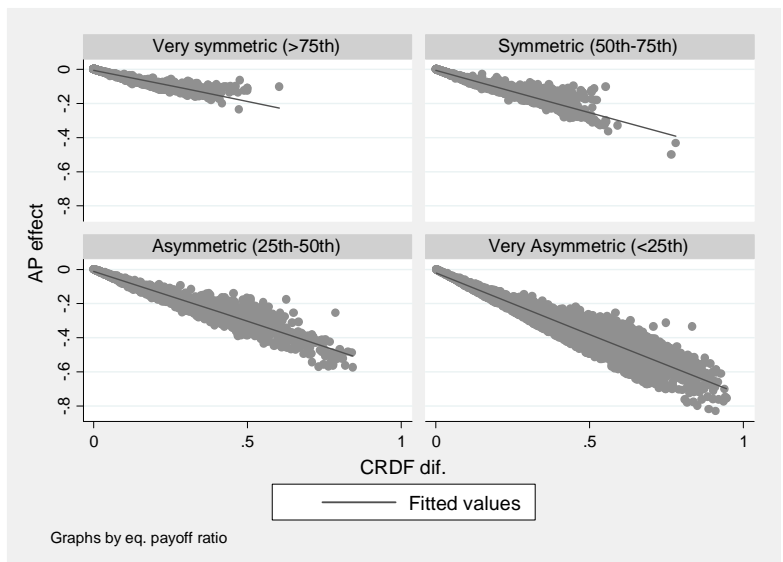

$\left.{ }^{*}\right)$ For the sake of exposition, it only considers cases where the CP effect is lower than 0.1

${ }^{(* *}$ It only considers mergers from Case (a) (as defined in Section 5.1.2)

Figure C.3 - Post-merger changes in equilibrium and deviation payoffs

Panel a) Post-merger equilibrium payoffs' change and pre-merger diversion ratios

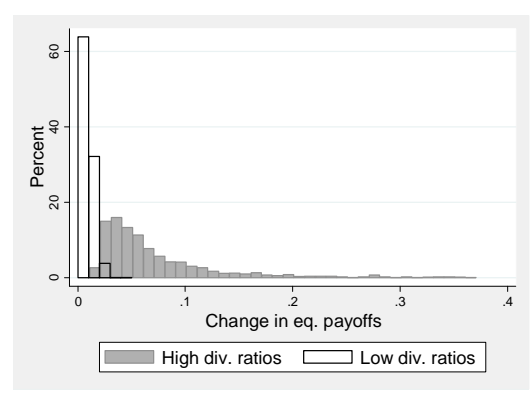

Panel c) Post-merger deviation payoffs' change and pre-merger diversion ratios

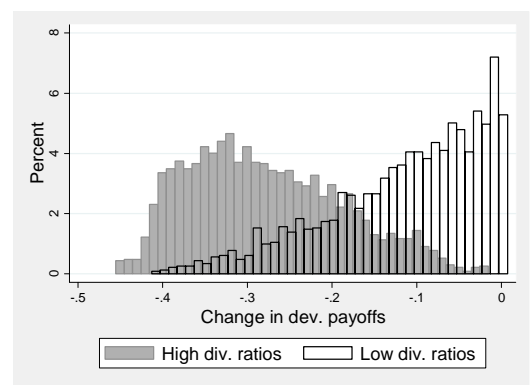

Panel b) Post-merger equilibrium payoffs' change and pre-merger own-price elasticities $\left(^{*}\right)$

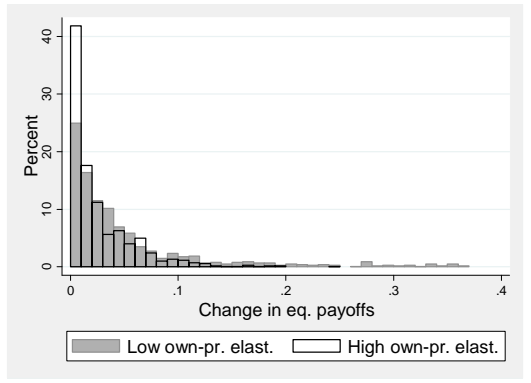

Panel d) Post-merger deviation payoffs' change and pre-merger own-price elasticities $\left(^{*}\right)$

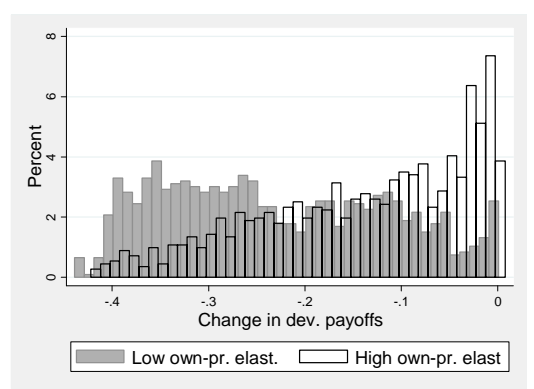

$\left.{ }^{*}\right)$ For the sake of exposition, it only considers equilibrium payoff's changes lower than the $99^{\text {th }}$ percentile value 
Figure C.4 - The magnitude of $\triangle C R D F$ (Merged firm) $\left({ }^{*}\right)$

Comparison between Cases a) and b)

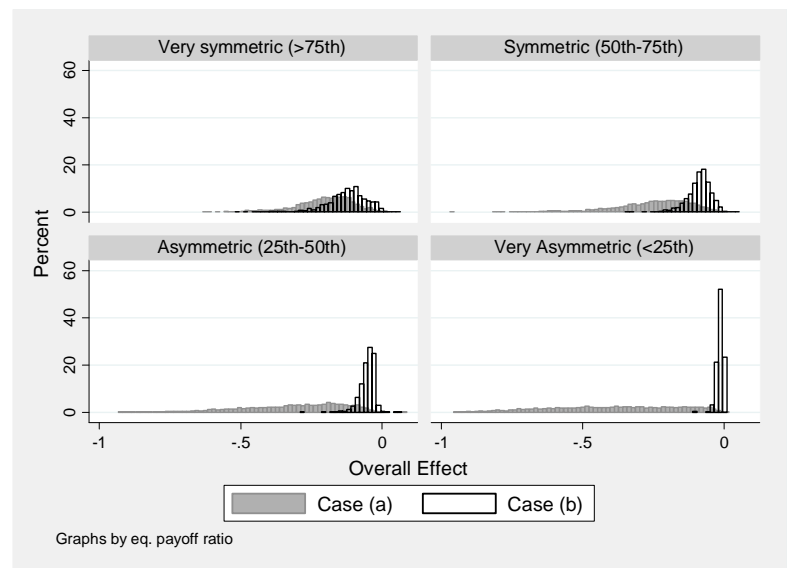

${ }^{*}$ ) For the sake of exposition, it only considers cases where the Overall Effect is lower than 0.1

\section{Figure C.5 - The magnitude of the CRDF change (Outsiders) $\left(^{*}\right)$}
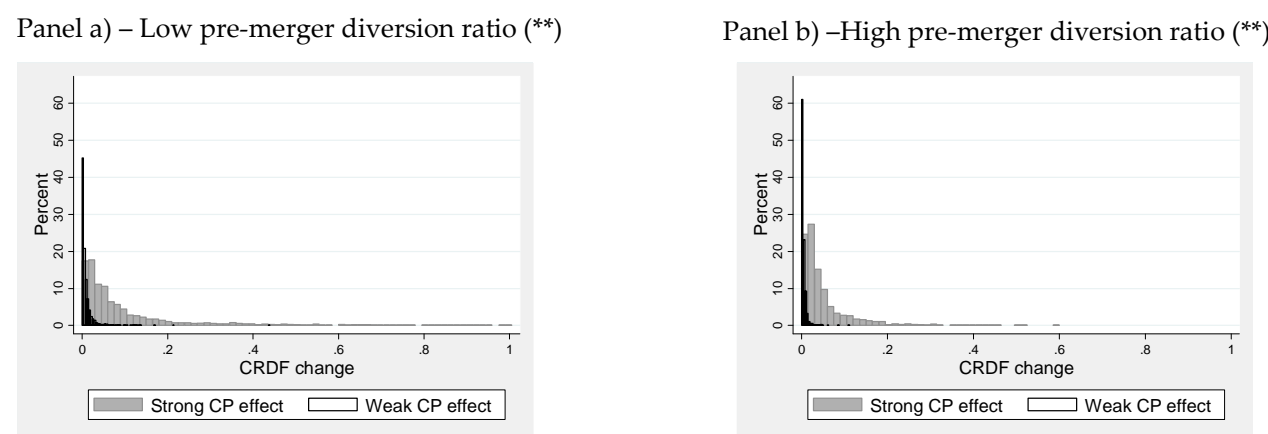

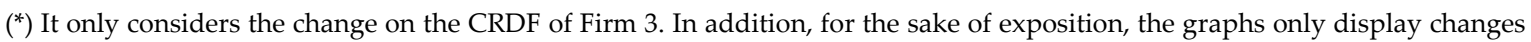
lower than 1

(**) Where "High diversion ratio" ("Low diversion ratio") stands for firms with a diversion ratio higher (lower) than the $50^{\text {th }}$ percentile value. While "Strong CP effect" ("Weak CP effect") stands for cases where the CP effect on the merged firm CRDF is higher (lower) than the $75^{\text {th }}\left(25^{\text {th }}\right)$ percentile value.

\section{References}

1. Aigner, Gisela, Oliver Budzinski \& Arndt Christiansen (2006), "The Analysis of Coordinated Effects in EU Merger Control: Where Do We Stand After Sony/BMG and Impala?," European Competition Journal, Vol. 2 (2), pp. 331-336.

2. Amelio, Andrea, Pablo Asbo, Miguel de la Mano, Ruben Maximiano and Viktor Porubsky (2009), “ABF/GBI Business: coordinated effects baked again," Competition Policy Newsletter, European Commission. Retrieved from: http://ec.europa.eu/competition/publications/cpn/2009_1_22.pdf 
3. Armantier, Olivier and Oliver Richard (2008), "Domestic airline alliances and consumer welfare," The RAND Journal of Economics Vol. 39, No. 3, Autumn 2008 pp. 875-904

4. Berry, Steven (1994), “Estimating Discrete-Choice Models of Product Differentiation," The RAND Journal of Economics, Vol. 25, No. 2. (Summer, 1994), pp. 242-262.

5. Berry, Steven, James Levinsohn and Ariel Pakes (1995), “Automobile Prices in Market Equilibrium," Econometrica, Vol. 63, No. 4. (Jul., 1995), pp. 841-890.

6. Bonnet, Céline and Pierre Dubois (2010), “Inference on vertical contracts between manufacturers and retailers allowing for nonlinear pricing and resale price maintenance," The RAND Journal of Economics Vol. 41, No. 1, Spring 2010 pp. 139-164

7. Brito, Duarte, Ricardo Ribeiro and Helder Vasconcelos (2013), “Quantifying the Coordinated Effects of Partial Horizontal Acquisitions," Retrieved from SSRN: $\underline{\text { http://ssrn.com/abstract=2282126 or }}$ http://dx.doi.org/10.2139/ssrn.2282126

8. Davis, Peter (2006), “Coordinated Effects Merger Simulation with Linear Demands," Competition Commission, Retrieved from http://citeseerx.ist.psu.edu/viewdoc/summary?doi=10.1.1.529.6672

9. Davis, Peter and Cristian Huse (2010), “Estimating the coordinated effects of mergers," Competition $\begin{array}{llll}\text { Commission, } & \text { January } & \text { Retrieved }\end{array}$ https://www.researchgate.net/profile/Cristian Huse/publication/228819163 Estimating the 'Coordinated Effe cts'_of_Mergers/links/0f31753509c7f4fb9c000000.pdf

10. Farrell, Joseph and Carl Shapiro (2010), “Antitrust Evaluation of Horizontal Mergers: An Economic Alternative to Market Definition," The B.E. Journal of Theoretical Economics: Vol. 10: Iss. 1 (Policies perspectives), Article 9

11. Friedman, James W. (1971), "A Non-cooperative Equilibrium for Supergames," The Review of Economic Studies, Vol. 38, No. 1 (Jan., 1971), pp. 1-12

12. Grigolon, Laura and Frank Verboven (2014), "Nested Logit or Random Coefficients Logit? A Comparison of Alternative Discrete Choice Models of Product Differentiation," The Review of Economics and Statistics, December 2014, Vol. 96, No. 5, Pages 916-935

13. Ivaldi, Marc, Bruno Jullien, Patrick Rey, Paul Seabright and Jean Tirole (2003), “The Economics of Tacit Collusion," Final Report for DG Competition, European Commission. Retrieved from http://ec.europa.eu/competition/mergers/studies_reports/the_economics_of_tacit_collusion_en.pdf

14. Knittel, Christopher and Konstantinos Metaxoglou (2014), "Estimation of Random-Coefficient Demand Models: Two Empiricists' Perspective," The Review of Economics and Statistics, March 2014, Vol. 96, No. 1, Pages 34-59

15. Milgrom, Paul and John Roberts (1994), "Comparing Equilibria," American Economic Review, American Economic Association, vol. 84(3), pages 441-59, June 
16. Moresi, Serge, David Reitman, Steven Salop and Yianis Sarafidis (2011), "Gauging Parallel Accommodating Conduct Concerns with the CPPI," September 8, 2011. Retrieved from SSRN: http://ssrn.com/abstract=1924516 or http://dx.doi.org/10.2139/ssrn.1924516

17. Moresi, Serge, David Reitman, Steven Salop and Yianis Sarafidis (2015), “cGUPPI: Scoring Incentives to Engage in Parallel Accommodating Conduct," August 14, 2015. Retrieved from http://www.crai.com/sites/default/files/publications/cGUPPI-Article-August-2015.pdf

18. Motta, Massimo (2000), “EC Merger Policy, and the Airtours Case,” European Competition Law Review, 21/ 4 (2000), 199-207

19. Nevo, Aviv (2000), "A Practitioner's Guide to Estimation of Random-Coefficients Logit Models of Demand," Journal of Economics \& Management Strategy, Volume 9, Issue 4, pages 513-548, Winter 2000.

20. Petit, Nicolas (2010), "Remedies for Coordinated Effects Under the EU Merger Regulation," Competition Law International, Vol. 6, No. 2, 2010

21. Sabbatini, Pierluigi (2015), "The Coordinated Effect of a Merger When Firms Share Collusion Gains Fairly," Retrieved from SSRN: http://ssrn.com/abstract=2333367 or http://dx.doi.org/10.2139/ssrn.2333367

22. Tirole, Jean (1988), “The Theory of Industrial Organization," The MIT Press 